\title{
Immunologie vitaler und konservierter Transplantate
}

\author{
C. Hammer ${ }^{1}$ und J. Bujía ${ }^{2}$ \\ ${ }^{1}$ Institut für Chirurgische Forschung (Direktor: Prof. Dr. med. K. Meßmer) und \\ 2 Universitäts-HNO-Klinik und Poliklinik (Direktor: Prof. Dr. med. E. Kastenbauer) Klinikum Großhadern, \\ Ludwig-Maximilians-Universität München, Marchioninistraße 15, W-8000 München 70
}

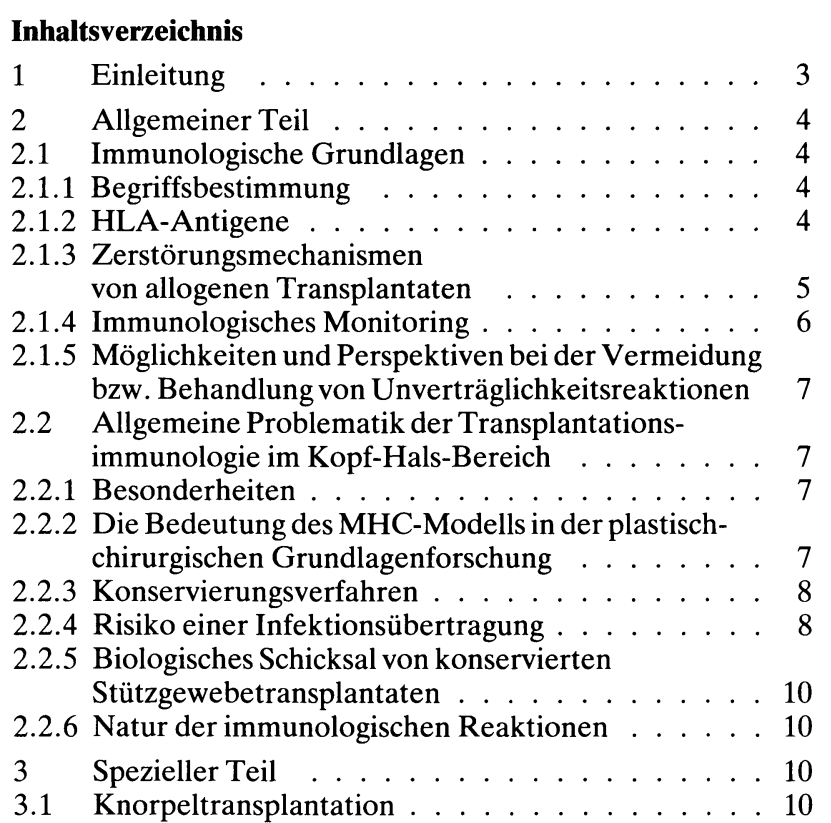

Inhaltsverzeichnis

1 Einleitung ............... 3

2 Allgemeiner Teil ............. 4

Immunologische Grundlagen $\cdot \cdot \cdot \cdot 4$

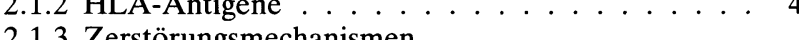

von allogenen Transplantaten $\ldots . . . . .55$

.1.4 Immunologisches Monitoring . . . . . . . . . . . .

bzw. Behandlung von Unverträglichkeitsreaktionen 7

Allgemeine Problematik der Transplantations-

immunologie im Kopf-Hals-Bereich . . . . . . . . 7

2.2.1 Besonderheiten . . . . . . . . . . . . 7

2.2.2 Die Bedeutung des MHC-Modells in der plastischchirurgischen Grundlagenforschung . . . . . . . 7

2.2.3 Konservierungsverfahren . . . . . . . . . . . . 8

2.2.4 Risiko einer Infektionsübertragung . . . . . . . . . 8

Biologisches Schicksal von konservierten

Natur der immunologischen Reaktionen . . . . . . 10

3.1 Knorpeltransplantation . . . . . . . . . . . . . . . 10

\section{Einleitung}

Die Transplantation von autologem und allogenem Gewebe im Kopf-Hals-Bereich ist heute eine weitverbreitete Methode, bei der Haut, Muskeln, Knochen, Knorpel und Faszien verpflanzt werden. Als Transplantate dienen unter anderem zusammengesetzte Gewebestücke aus Haut-Knorpel-Haut (z.B. composite graft), Haut-Muskel (z.B. myokutane Lappen), Haut-Muskel-Knochen (z.B. osteokutaner Inguinallappen). Diese werden entweder aus der Region verschoben oder müssen frei bzw. frei mit mikrovaskulärer Anastomose eingepflanzt werden. Bei der allogenen bzw. xenogenen Transplantation handelt es sich im wesentlichen um sogenannte freie Transplantate (ohne Gefäßanastomose), die als Er-
3.1.1 Konservierungsverfahren . . . . . . . . . . . 11

3.1.2 Antigenität von Knorpelgewebe . . . . . . . . . . 11

3.1.3 Rolle der HLA-Klasse-II-Antigene im immunologischen Verhalten allogener Knorpeltransplantate . . . . . . . . . . 12

3.1.4 Charakterisierung der immunologischen Reaktionen gegenüber Knorpeltransplantaten . . . . . . . . . 14

3.2 Knochentransplantation . . . . . . . . . . . 14

3.2.1 Antigenität von Knochengewebe . . . . . . . . . 14

3.2 .2 Osteoinduktion . . . . . . . . . . . . . 15

3.2.3 Konservierungsverfahren . . . . . . . . . . 15

3.2.4 Charakterisierung der immunologischen Reaktionen gegenüber Knochentransplantaten . . . . . . . . 16

3.3 Bindegewebstransplantation . . . . . . . . . . 17

3.3.1 Trommelfelltransplantate . . . . . . . . . 17

3.3.2 Bindegewebstransplantate . . . . . . . . . . . 17

3.4 Tracheatransplantation . . . . . . . . . . 18

3.4.1 Antigenität der Trachea . . . . . . . . . . . 18

3.4.2 Einfluß unterschiedlicher Konservierungsverfahren auf die Antigenität der Trachea . . . . . . . . . 18

4 Ausblick ............... 19

Literatur . . . . . . . . . . . . . . . 19 satzmaterialien zum Defektausgleich verwendet werden.

Die langjährige klinische Erfahrung und die experimentelle Grundlagenforschung zeigen, daß autologe Transplantate das beste Material zur Rekonstruktion großer Defekte darstellen. Da jedoch die körpereigenen Vorräte begrenzt sind und andere vergleichbare Implantate nicht zur Verfügung stehen, ist die Anwendung von allogenen Materialien gerechtfertigt. Im Kopf-Hals-Bereich werden heutzutage allogener Knorpel, Knochen, Faszien und Trachea verwendet. Als xenogene Transplantate finden nur selten Knorpel und Faszien eine klinische Anwendung.

Die Verwendung von allogenen Transplantaten ist wegen Unverträglichkeitsreaktionen nicht unpro- 
blematisch. Inwieweit und wie rasch eine AbstoBungsreaktion eintritt, ist von mehreren Faktoren abhängig, z.B. ob das Transplantat primär oder sekundär vaskularisiert ist, Lymphanschluß besitzt, antigenpräsentierende Zellen enthält, physikalisch oder chemisch vorbehandelt wurde, und ob das Immunsystem des Empfängers supprimiert ist. Der Hauptfaktor ist jedoch die genetisch determinierte immunologische Verträglichkeit, und damit die Histokompatibilität. Wird einem Organismus Gewebe eines anderen Organismus eingepflanzt, beginnt eine komplexe Wechselwirkung zwischen Empfängerund Transplantatgewebe. Sind die Gewebe nicht genetisch identisch, greifen immunkompetente Zellen des Empfängers das Transplantat an. Außerdem können mit dem Transplantat Infektionskrankheiten übertragen werden und so den Erfolg der Transplantation zunichte machen.

Die vorliegende Übersicht versucht eine zusammenfassende Darstellung theoretischer und experimenteller Probleme der Transplantation von vitalen und konservierten Geweben (Knorpel, Knochen, Bindegewebe) im Kopf-Hals-Bereich, soweit sie für den Chirurgen von Interesse sind.

\section{Allgemeiner Teil}

\subsection{Immunologische Grundlagen}

Die immunologische Natur der Abstoßung übertragener körperfremder Gewebe oder Organe ist schon seit der Jahrhundertwende bekannt. Erst der tierexperimentelle Nachweis individualspezifischer Gewebseigenschaften hat den wissenschaftlichen $\mathrm{Zu}$ gang zur Transplantationsimmunologie eröffnet. Für menschliches Gewebe wurden diese Eigenschaften 1958 als „HLA-Merkmale“ beschrieben [54]. Ihre Immunogenität wurde als Ursache für die Abstoßung von Organen bei der Übertragung von einer Person auf eine andere erkannt. Zeitgleich mit dem neuen Wissen wurden erste erfolgreiche Gewebe- und Organtransplantationen durchgeführt.

\subsubsection{Begriffsbestimmung}

Verpflanzungen körpereigenen Gewebes werden als autologe Transplantation (z.B. autologer Rippenknorpel) bezeichnet; bei Gewebeübertragungen genetisch identischer Individuen (eineiige Zwillinge) spricht man von isogener Transplantation. Unter allogener Transplantation versteht man die Übertragung von Gewebe bzw. Organen von einem Individuum auf ein anderes derselben Spezies (z.B.
Tabelle 1. International anerkannte Begriffsbestimmung zur Transplantation

\begin{tabular}{ll}
\hline Bezeichnung & Erläuterung \\
\hline autolog & eigener Organismus \\
isogen & genetisch identisches Individuum \\
allogen & $\begin{array}{l}\text { genetisch differentes Individuum gleicher } \\
\text { Spezies }\end{array}$ \\
xenogen & Individuum fremder Spezies \\
\hline
\end{tabular}

Mensch zu Mensch). Transplantationen zwischen Individuen verschiedener Spezies, z.B. von Tier auf Mensch werden als xenogene Transplantationen (auch Heterotransplantationen) bezeichnet. Der Einsatz von Fremdmaterialien wie Metall oder Kunststoff wird als alloplastische Implantation bezeichnet und entspricht beispielsweise der Verwendung eines Drahtsteigbügels nach Stapedektomie (Tabelle 1) [274].

Ein Organ kann entweder orthotop, d.h. an die gleiche Stelle im Körper oder heterotop, d.h. an eine andere Stelle im Körper implantiert werden. Dient ein Transplantat nur der zeitweisen Überbrückung eines Defektes, sprechen wir von einer homostatischen oder Gewebetransplantation. Kann dagegen das transplantierte Organ nicht vom Empfänger ersetzt werden und soll es seine Funktion ohne zeitliche Begrenzung ausüben, handelt es sich um eine homovitale oder Organtransplantation [190].

Die Transplantation zwischen genetisch nicht identischen Individuen (allogene und xenogene Transplantation) endet häufig infolge von Histoinkompatibilität in einer Abstoßungsreaktion. Eine wichtige Rolle spielen dabei die individuum- und speziesspezifischen Antigene. Sie werden vom Empfänger als fremd erkannt und lösen eine Immunantwort aus. Zwei hauptsächliche Antigensysteme stellen die Histokompatibilitätsbarriere zwischen Spender und Empfänger dar. Es handelt sich dabei um die Blutgruppenantigene (ABO-System) und die HLA-Antigene.

\subsubsection{HLA-Antigene}

Antigene sind Moleküle, die in einem Organismus eine Immunantwort auslösen (Immunogenität) und zum anderen mit dem „Produkt“ dieser Antwort, dem Antikörper, spezifisch reagieren.

Bei höheren Tierarten gibt es einen Genort, Haupthistokompatibilitätskomplex $(\mathrm{MHC}=$ Major Histocompatibility Complex) genannt, der für starke allogene Reaktionen verantwortlich ist und stark immunogen wirkt $[47,265]$. Das HLA-System (HLA = Human Leucocyte Antigen) stellt den Haupthisto- 
kompatibilitätskomplex des Menschen dar. Es wird von Genen, die auf dem kurzen Arm des Chromosoms 6 liegen, kodiert [131, 153]. Die sogenannten HLA-Klasse-I-Antigene werden von den Genloci HLA-A, -B bzw. -C und die Klasse-II-Antigene von den Genorten HLA-DP, -DR und -DQ kodiert (Abb. 1). Die Struktur von Antigenen der Klasse I unterscheidet sich von der der Klasse-II-Antigene. Die HLA-Klasse-I-Antigene bestehen aus einer glykolisierten Polypeptidkette mit einem Molekulargewicht um 45.000 D (schwere Kette), die mit einem nichtglykolisierten Peptid (beta-2-Mikroglobulin, MG etwa $12.000 \mathrm{D}$, leichte Kette) nichtkovalent assoziiert ist. Das schwere Glykoprotein besitzt drei globuläre Domänen [50]. Die Klasse-II-Antigene bestehen aus zwei verschiedenen Polypeptidketten (einer alpha- und einer etwas leichteren beta-Kette, MG 28.000 D). Jede Kette besitzt zwei globuläre Domänen (Abb. 2) [146].

Die HLA-Antigene repräsentieren die immunologische Identität einer Zelle. Die quantitative Ausprägung der HLA-Antigene auf der Zelle wird von zahlreichen Faktoren beeinflußt. Gesteigert wird sie unter anderem durch Interferon und Lipopolysaccharide [46, 76, 192, 228, 260, 261].

Die Klasse-I-Antigene sind auf allen kernhaltigen Zellen des Organismus zu finden. Eine Ausnahme hierfür scheinen die plazentaren Trophoblasten zu sein $[4,21]$. Im Gegensatz zu den Klasse-IAntigenen befinden sich die Klasse-II-Antigene normalerweise nur auf wenigen menschlichen Körperzellen mit myeloischem oder lymphoidem Ursprung, z.B. auf Lymphozyten und Makrophagen [109, 121, 230]. Neuere Arbeiten berichten jedoch über eine breitere Verteilung von Klasse-II-Antigenen auf Geweben mit nicht myeloischem oder lymphoidem Ursprung [52, 78, 79, 142, 271].

Die Klasse-I-Antigene dienen als Target-Antigene der zytotoxischen T-Lymphozyten und sind daher für die Abstoßungsreaktion von besonderer Be-

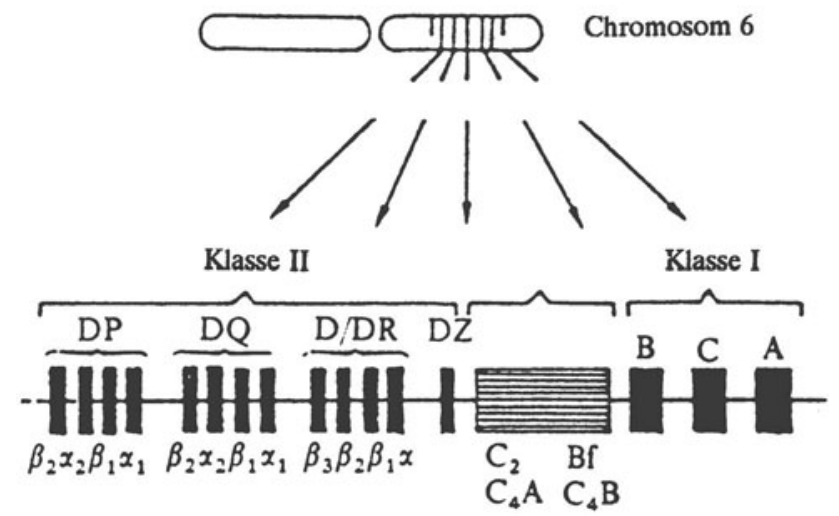

Abb. 1. Genkartierung der Region des Chromosoms 6 des Menschen mit Darstellung des HLA-Genkomplexes

deutung [168]. Die Zellen, die Klasse-II-Antigene tragen, dienen als antigenpräsentierende Zellen [9, $110,120,153,171]$. So können Antigene, die von Makrophagen präsentiert werden, nur dann von T-Helfer-Lymphozyten erkannt werden, wenn die Antigene als Komplex mit Klasse-II-Antigenen präsentiert werden (Abb. 3). Die stimulierten T-Lymphozyten setzen Lymphokine frei, die wiederum andere Zellen für die Immunantwort rekrutieren [196]. Die HLA-Klasse-II-Antigene sind deshalb für die Regulation und insbesondere die Intensität der Immunantwort und damit der Abstoßungsreaktion von besonderer Bedeutung [85, 168].

\subsubsection{Zerstörungsmechanismen von allogenen Transplantaten}

Die immunologische Gewebeunverträglichkeit zwischen Spender und Empfänger führt im allgemeinen zu einer Zerstörung und Abstoßung allogener Transplantate durch den Empfängerorganismus. Diese Unterschiede in den Gewebseigenschaften führen zur Ausbildung zellulärer und humoraler Effektor-
Abb. 2. Struktur der HLA-Moleküle. HLA-I $=$ HLA-Klasse-I-Antigene. HLA-II = HLA-Klasse-II-Antigene

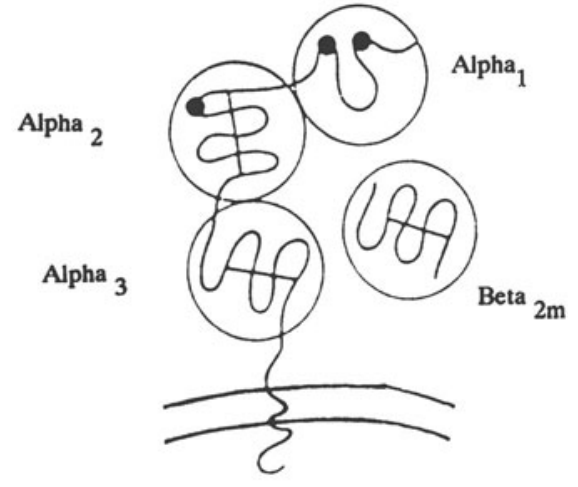

HLA-I

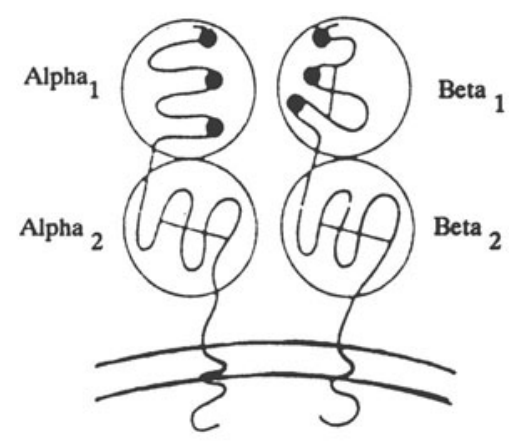

HLA-II 
6

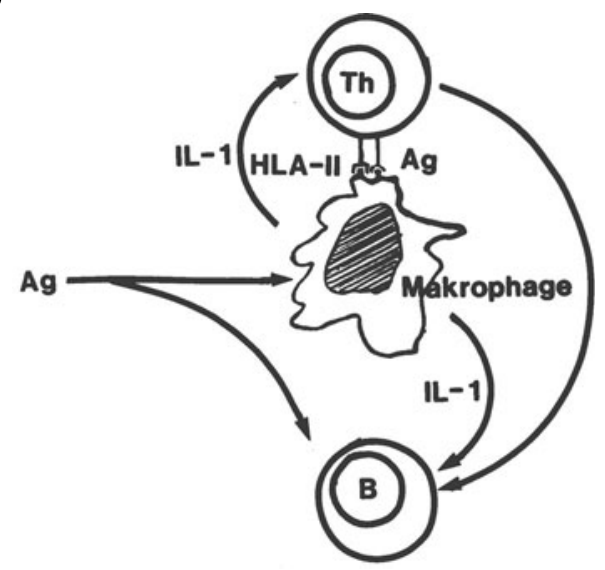

Abb. 3. Kooperation zwischen antigenpräsentierenden Zellen, T-Zell-Subpopulationen und B-Zellen. B-Zellen $(B)$ und TZellen, z.B. Helfer-T-Zellen (Th), sind nicht in der Lage, freies Antigen $(A g)$ zu erkennen; um erkannt zu werden, muß das Antigen zusammen mit HLA-Antigenen der Klasse-II (HLAII) präsentiert werden. Diese Funktion wird von Zellen übernommen, die antigenpräsentierende Zellen genannt werden (z.B. Makrophagen)

Systeme, die ihrerseits mit dem fremden Gewebe reagieren und es zerstören [179].

Die Aktivierung des Systems unterliegt einer komplizierten Steuerung [9]. Sie hat große praktische Bedeutung erlangt, weil sich hier Ansatzpunkte therapeutischer Manipulation bieten. Man unterscheidet eine Induktions-, eine Regulations- und eine Effektorphase (Abb. 4). Während der Induktionsphase nehmen Makrophagen/Monozyten das fremde Antigen auf und präsentieren es den T-Helfer-Zellen. Diese nehmen das Signal auf und geben es den diversen Effektorzellen, die nun ihrerseits aktiviert werden, weiter. In der Regulationsphase wird die Entwicklung der Immunantwort entweder durch Helfer-Zellen verstärkt oder durch Suppressor-Zellen blockiert. Eine Vielzahl von Botenstoffen (Zytokine) verknüpft die beteiligten Zellelemente in einem komplizierten Regel- und Rückkoppelungsmechanismus. In der Effektorphase wirken die beteiligten Zellen in unterschiedlicher Gewichtung zusammen. In vereinfachter Form: zelluläre Mechanismen sind um so ausgeprägter, je akuter eine Gewebeabstoßung ist, während Antikörper um so stärker vorherrschen, je chronisch-schleichender der Vorgang abläuft. Humorale Vorgänge beruhen auf der Bildung von Antikörpern, die gegen das Transplantat gerichtet sind. Diese Antigen-Antikörper-Bindung aktiviert das Komplement-System mit allen Folgen bis hin zu massiver Entzündung und Zerstörung des getroffenen Gewebes. Zelluläre Effektoren zerstören das Transplantat durch direkten Kontakt mit dem Gewebe. Die an einer Abstoßung beteiligten zellulären Reaktionen werden überwiegend

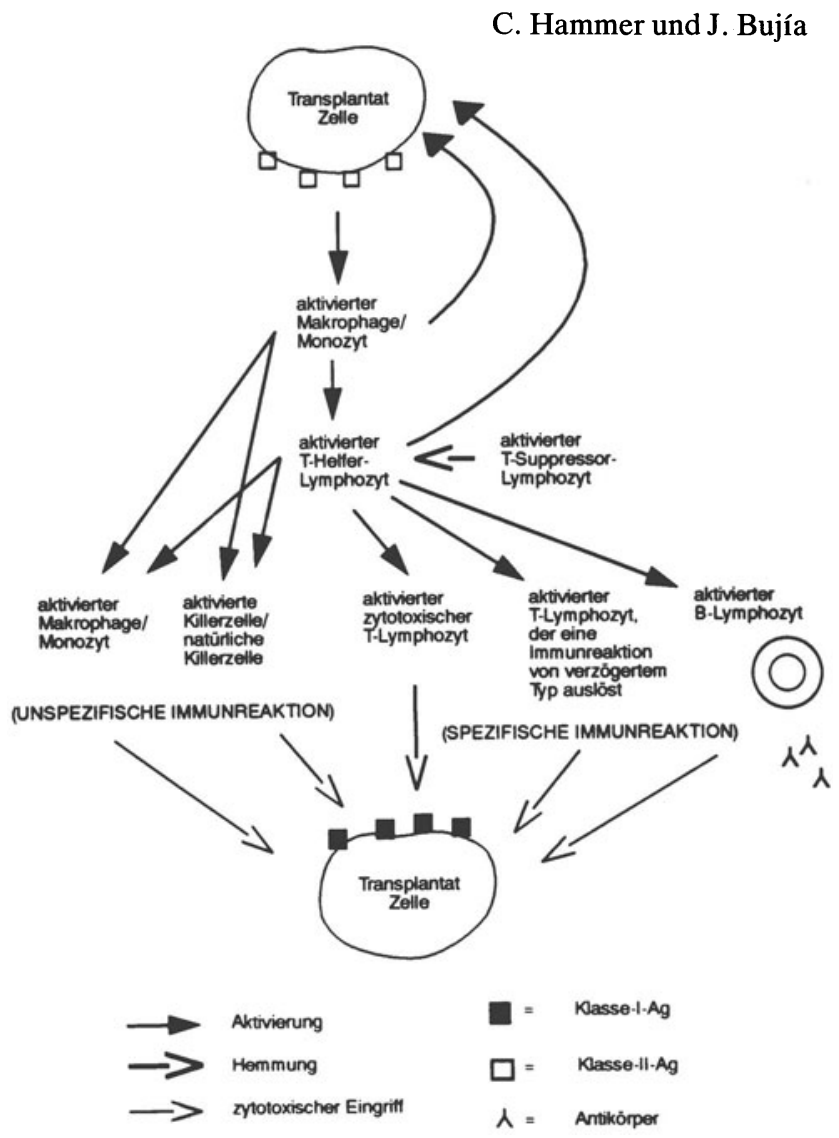

Abb. 4. Übersicht über die Induktions-, Regulations- und Effektorphase der Immunantwort gerichtet gegen Transplantatzellen bei der Abstoßungsreaktion

durch T-Lymphozyten vermittelt und bilden eine Immunreaktion vom verzögerten Typ (Typ IV) [168].

Allogene Zellen, die Klasse-II-Antigene tragen, aktivieren selbst die T-Helferzellen des Empfängers, d.h. sie präsentieren ohne Beteiligung von Makrophagen ihr Antigen selbst. Eine TransplantatabstoBung ist daher besonders $\mathrm{zu}$ befürchten, wenn Klasse-II-Antigene tragende Zellen im Spendergewebe vorhanden sind, z.B. Spender-Lymphozyten $[13,51,92]$.

\subsubsection{Immunologisches Monitoring}

Die von Köhler und Milstein [144] etablierte Technik zur Produktion monoklonaler Antikörper führte in den letzten Jahren zu einem gewaltigen Erkenntniszuwachs auf dem Gebiet der humanen zellulären Immunologie [6]. Die Analyse zirkulierender oder in situ lokalisierter Immunzell-Populationen in Patienten erlaubte, das im letzten Jahrzehnt erarbeitete Wissen über das Immunsystem im Menschen zu erproben. Gleichzeitig wurden zytologische, histologische und immunologische Tests unterschiedlicher Invasivität entwickelt, die die immunologischen Pro- 
zesse, die sich nach einer Transplantation abspielen und die das Schicksal des Transplantates bestimmen, charakterisieren sollen. Dies führte dazu, diagnostische Tests zu entwickeln, die nicht auf klinischen Befunden beruhen, d.h. Parametern, die einen Funktionausfall erkennen lassen, sondern die die Ursachen der Abstoßung, das heißt die ,immunologische Umorientierung“ des Immunsystems berücksichtigen [108].

Bei einer Abstoßungsreaktion kommt es zu charakteristischen Veränderungen innerhalb des Immunsystems. Immunkompetente Zellen werden aktiviert und setzen Zytokine frei. Die Untersuchung der Zusammensetzung und Eigenschaften der Infiltratzellen mittels monoklonaler Antikörper im Biopsiematerial können Hinweise auf das Auftreten und die Stärke der Abstoßungsreaktion geben [82, 104, 218].

Durch das sogenannte „Zytoimmunologische Monitoring" (ZIM) können lichtmikroskopisch immunkompetente Zellen im peripheren Blut nachgewiesen werden [106]. Dabei ist es möglich, durch die Berücksichtigung von aktivierten Lymphozyten, Lymphoblasten und „large granular lymphocytes“ das Auftreten sowohl von Abstoßungsreaktionen als auch von viralen und bakteriellen Infektionen zu bestimmen [107]. Der Einsatz von monoklonalen Antikörpern erlaubt die Durchführung quantitativer durchflußzytometrischer Analysen von Lymphozytensubpopulationen (CD3, CD4 und CD8) [105, 145]. Weiterhin ist es möglich, Zellaktivierungszustände an den Makrophagen und Lymphozytenpopulationen durch den Nachweis der Expression von Aktivierungsmarkern auf der Zelloberfläche (HLA-DR Antigene und IL-2-Rezeptoren) zu erkennen [23, 197, 210]. Andere Methoden, wie z.B. die selektive Darstellung des DNA-Gehalts (PI-Assay) und Chemolumineszenz, die eine Bestimmung von funktionellen Parametern an der Immunzelle erlauben, werden heute intensiv erforscht. Sie werden bereits im „immunologischen Monitoring“von transplantierten Patienten eingesetzt $[42,158]$. Schließlich können die Zytokine mittels sehr empfindlicher ELISA- und RIA-Methoden untersucht werden [124, 170]. Erhöhte Zytokin-Spiegel deuten auf eine Aktivierung des Immunsystems und auf eine beginnende $\mathrm{Ab}$ wehrreaktion hin.

\subsubsection{Möglichkeiten und Perspektiven bei der Vermeidung bzw. Behandlung von Unverträglichkeitsreaktionen}

Erstes Ziel muß es sein, ABO- und HLA-Differenzen zwischen Spender und Empfänger zu vermeiden.
Wenn die Histoinkompatibilität des Transplantats durch diese Angleichung auch drastisch reduziert werden kann, so können verbleibende, fast nie völlig zu vermeidende Differenzen das übertragene Transplantat immer noch gefährden. Dies ist die Domäne der suppressiven Therapie. Die medikamentöse Immunsuppression verwendet Substanzen (Ciclosporine), die das Immunsystem in unspezifischer Weise hemmen und darüber hinaus in ihrer Wirkung nicht auf das Immunsystem begrenzt sind. Die Therapie mit diesen Medikamenten ist deshalb mit einer Reihe von Nebenwirkungen und Komplikationen belastet.

Ziel der Forschung auf diesem Gebiet ist die Entwicklung von Substanzen, die eine gezieltere Intervention im Immunsystem ermöglichen. Ein Schlüssel hierzu könnten monoklonale Antikörper sein, die gegen Zellen und Moleküle gerichtet sind, die den Abstoßungsvorgang auslösen. Ein Beispiel ist die Anwendung von monoklonalen Antikörpern gegen den T-Zell-Rezeptor (CD-3 Komplex) [169, 213, 231], gegen Subsets von T-Lymphozyten (insbesondere gegen CD-4 Zellen) [48], gegen Aktivierungsantigene (IL-2 Rezeptor) [141, 197] und gegen antigenpräsentierende Zellen des Transplantats [75].

\subsection{Allgemeine Problematik der Transplantationsimmunologie im Kopf-Hals-Bereich}

\subsubsection{Besonderheiten}

Die wesentlichen Aufgaben des freien Gewebetransplantats im Kopf-Hals-Bereich sind Defektauffüllung und mechanische Abstützung. Der Erfolg einer Transplantation wird bestimmt von der Einheilung und der Formbeständigkeit bzw. Widerstandsfähigkeit gegen mechanische Beanspruchung sowie der Dauerhaftigkeit des erzielten Resultates. Unverträglichkeitsreaktionen und Infektionen sind die Hauptprobleme bei der allogenen Transplantation. Im Kopf-Hals-Bereich stellen mögliche Teilresorptionen und Verbiegungen des verpflanzten Gewebes, die das gewünschte funktionelle oder kosmetische Ergebnis beeinträchtigen, ein zusätzliches Problem dar [138].

\subsubsection{Die Bedeutung des MHC-Modells in der plastisch-chirurgischen Grundlagenforschung}

Wie in Punkt 2.1.2 schon ausführlich erklärt wurde, sind Klasse-I- und -II-Antigene die wesentlichen Determinanten des Schicksals eines verpflanzten alloge- 
nen Transplantats. Dabei aktivieren Klasse-II-Antigen-tragende allogene Zellen des Spenders selbst die T-Helfer-Zellen des Empfängers, d.h. sie präsentieren ihr Antigen selbst. Eine Transplantatabstoßung ist daher zu befürchten, wenn Klasse-II-Antigenetragende Zellen im Spendergewebe vorhanden sind, z.B. Spender-Lymphozyten [13, 51]. Vor dem Hintergrund dieser theoretischen Überlegungen ist es die Zielsetzung einiger Arbeitsgruppen, selektiv mittels in vitro Kultur - ohne die Vitalität des Transplantates $\mathrm{zu}$ beeinträchtigen, die antigenpräsentierenden Zellen daraus zu eliminieren und damit die Immunogenität von allogenen Transplantaten $\mathrm{zu}$ vermindern.

Die Präsenz von HLA-Antigenen in Gewebetransplantaten war Gegenstand zahlreicher Untersuchungen. Es konnte gezeigt werden, daß Klasse-IAntigene auf allen kernhaltigen Zellen des Organismus und daher auch im Transplantatgewebe vorhanden sind [4, 21]. Die Existenz von Klasse-II-Antigenen zeigt große Unterschiede zwischen verschiedenen Tierspezies. Nähere Details über die Verteilung von HLA-II-Antigenen im menschlichen Knorpel, Trachea und Knochen werden später diskutiert.

Im allgemeinen wird die allogene Transplantation im Kopf-Hals-Bereich ohne die Berücksichtigung einer ABO- und HLA-Typisierung durchgeführt, da Untersuchungen bewiesen, daß dies nicht notwendig ist [85]. Nur bei der Knochentransplantation in anderen Fachgebieten, wie der Orthopädie, wo große Mengen von Knochengewebe transplantiert werden, ist man anderer Auffassung. Während einige Zentren ABO- und sogar rhesuskompatibel transplantieren, nehmen andere Zentren darauf keine Rücksicht.

\subsubsection{Konservierungsverfahren}

Ziel und Zweck einer Konservierung ist es einerseits, das Gewebe vor der Zersetzung zu bewahren, wobei das Transplantat durch die Manipulation nicht zu stark verändert werden soll. Erstrebenswert ist andererseits der Verlust der antigenen Eigenschaften.

Man unterscheidet eine Konservierung unter Erhaltung der Vitalität von einer Konservierung, bei der das Transplantat durch Anwendung von physikalischen (Tiefgefrieren, Lypophilisieren, Bestrahlen, Erhitzen) oder chemischen Mitteln avital wird. Die wichtigsten chemischen Gewebskonservierungsmittel beschränken sich auf Formalin, Alkohol und Lösungen organischer Schwermetallsalze (z.B. Cialit und Merthiolat). Die letzteren haben sich in der HNO-Heilkunde besonders bewährt [138, 165, 180, 186]. Cialit (Äthylmercuriothiosalicylsäure Natrium-
Salz) und Merthiolat (2-Äthyl-mercurimercaptoBenzoxazol-5-carbonsaures Natrium) sind organische Quecksilber-Verbindungen, die eine hohe Affinität zu den Thiolgruppen der Proteine besitzen. Darin scheint die konservierende Wirkung der Lösungen zu liegen. Veränderungen an der Sekundärstruktur von Enzymproteinen mit essentiellen SHGruppen bedingen deren Inaktivierung. Bei Strukturproteinen führt diese Umsetzung zur Denaturierung, wodurch in der Regel eine Verringerung der Löslichkeit erzielt wird [164]. Mit der Reduzierung der Löslichkeit scheint auch eine Abnahme der Antigenität der Transplantate einher zu gehen. Eigene Untersuchungen haben gezeigt, daß die Wirksamkeit von Cialit und Merthiolat auf eine Zerstörung von Klasse-II-Antigenen zurückzuführen ist. So soll bei der Konservierung mit Merthiolat und Cialit das Transplantat mindestens 42 Tage behandelt werden, um eine totale Elimination von Klasse-II-Antigenen zu gewährleisten [30].

Ein wichtiges zusätzliches Problem ergibt sich aus der Tatsache, daß die Konservierung zu einer Devitalisierung des Gewebes führt [101, 102, 128, 156]. Einige der Resorptionsphänomene werden auf eine schlechte Konservierung des Transplantats zurückgeführt. Der Gedanke, daß durch die Konservierung die biologische Güte des Transplantats verändert werden kann, motivierte uns in der Suche von Kriterien und Methoden, mit denen man die Qualität des Transplantats bei der Entnahme aus dem Spenderorganismus oder den durch die Lagerung bedingten Qualitätsverlust bestimmen könnte. Mit Hilfe der Protonen-Magnetresonanzspektroskopie, einer Methode, die eine berührungsfreie Überprüfung von Gewebe ermöglicht, ist es uns gelungen, einige der lagerungsbedingten Veränderungen im Knorpelstoffwechsel aufzuspüren. Durch die Beurteilung der anaeroben Glykolyse und damit indirekt der Gewebshypoxie wie auch des Grades der makromolekularen Auflösungsund Umwandlungsprozesse in der extrazellulären Matrix ist es möglich, die biologische Güte des Spendergewebes vor und nach der Transplantation zu erfassen (Abb. 5) [35, 201, 202, 203]. Diese Methode könnte in Zukunft eine Optimierung der verschiedenen Konservierungsverfahren ermöglichen.

Ein weiterer Nachteil ist, daß die Konservierungsverfahren eine gewisse Konsistenzminderung bewirken können. Dies versucht man durch Präfixierung mit Formaldehyd zu überwinden [30, 181].

\subsubsection{Risiko einer Infektionsübertragung}

Da Organ- und Gewebetransplantate potentiell infektiös sind, ist eine ausreichende Bakterizidie und 

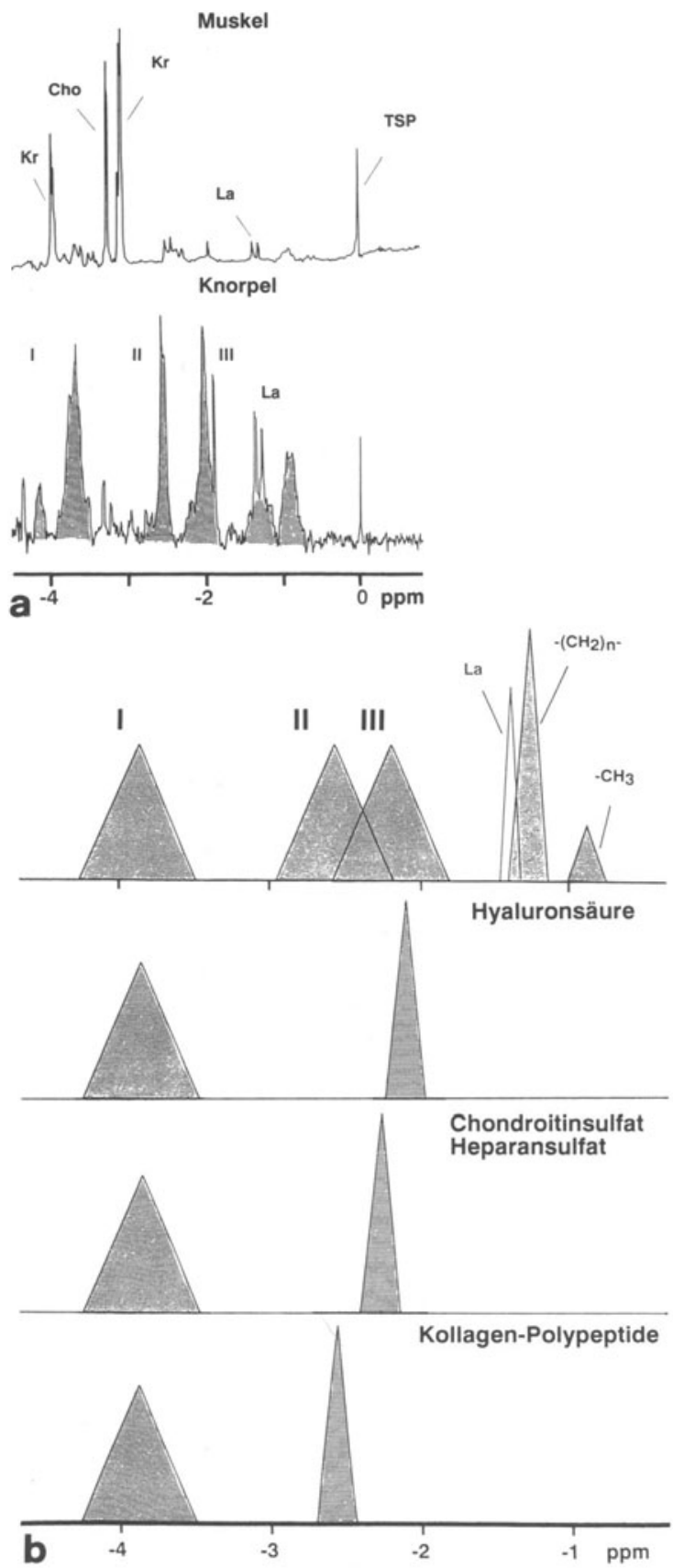

Abb. 5. a $^{1}$ H-Spektren einer Gewebeprobe der Muskulatur und des Knorpels. Die Spektren des Knorpels zeigen eine Vielzahl von breiten Resonanzbanden (I, II und III), die mit Hilfe der Spektren von isolierten Substanzen (b) den makromolekularen Strukturen der Grundbestandteile der extrazellulären Knorpelmatrix (Proteoglykane und Kollagene) zuzuordnen sind [35, 201-203]

Viruzidie für ein Konservierungsmittel unabdingbar. Inwieweit die unterschiedliche Aufarbeitung die Infektiosität reduziert, ist derzeit noch in der Diskussion.

Die Konservierung hat zwei grundsätzliche Ziele. Zum einen soll, wie schon genannt wurde, die potentielle Antigenität der körperfremden Gewebe vermindert werden. Zum anderen sollen die Transplantate keimfrei sowie langfristig lagerbar werden.

In Zusammenhang mit der Sterilität wird die antibakterielle Wirkung des Cialits in letzter Zeit kritisch gesehen. Bakteriologische Untersuchungen konnten zeigen, daß typische Krankheitserreger bei der chronischen Otitis media nicht abgetötet werden $[61,126,173]$.

Ein zusätzliches und wesentlich größeres Problem aus klinischer und forensischer Sicht ist die mögliche ungenügende Verhinderung der Übertragung von viralen Krankheiten vom Spenderorganismus auf den Empfänger [98, 181, 195, 209, 214, 227]. In diesem Zusammenhang geriet die allogene lyophilisierte Dura in den letzten Jahren in die Diskussion, wobei sich die Berichte über die mittels lyophilisierter Dura übertragene Creutzfeld-Jakob-Erkrankung, eine Slow-Virus-Infektion, häuften. Keiner dieser Berichte konnte jedoch eindeutige Beweise erbringen [22, 27, 62, 87, 94, 167, 174, 194, 237]. Mit der Zunahme der Transplantationsfrequenz treten zwei andere Virusinfektionen immer mehr in den Vordergrund: Hepatitis B und AIDS. Bei diesen Infektionskrankheiten beträgt die Mortalität $10 \%$ bzw. bis $\mathrm{zu} 100 \%$. Insbesondere der HIV-Infektion kommt derzeit größte aktuelle Bedeutung zu.

In Hinblick auf den Mechanismus der HIVÜbertragung wird der Vermehrungszyklus dieses Virus durch den Befall von Zellen eingeleitet, die einen spezifischen Rezeptor, das CD4-Antigen an der Zelloberfläche tragen [53]. Dieser spezifische Oberflächenrezeptor wurde bisher an B-Lymphozyten, THelfer-Zellen, Makrophagen, Megakaryozyten, Gliazellen und Endothelzellen nachgewiesen [84, 207, 238]. Nun stellt sich die Frage, ob im Transplantatgewebe CD4-positive Zellen zu finden sind. Chondrozyten und Knochenzellen tragen keine CD-4-Antigene. Gewebe, die gut durchblutet sind, enthalten reichlich Endothelzellen, die aufgrund ihrer Antigene HIV übertragen können. Dies trifft für Knorpel, ein gefäßloses Gewebe, nicht zu.

Auf jeden Fall sollten bei der Gewebeübertragung einige Sicherheitsmaßnahmen ergriffen werden. Ist bei der Transplantation der Immunstatus des Spenders nicht bekannt, so muß zumindest durch die Konservierung jedes Risiko der Übertragung einer Krankheit ausgeschlossen sein. Bezüglich der Stabilität des HIV bzw. dessen Inaktivierung gibt es eine Vielzahl von Untersuchungen. Thermisch und chemisch ist das HIV relativ einfach zu inaktivieren $[8,12,57,60]$. Weiterhin liegen Untersuchungen über die Stabilität DNS-integrierter Viren vor, die zeigen, daß ein Virusnachweis nach der chemischen bzw. physikalischen Konservierung nicht mehr möglich ist [270]. 
Es ist sinnvoll, das Infektionsrisiko bei der Organübertragung in der Größenordnung einer Bluttransfusion zu sehen. Organspender sollen daher auch mindestens den Anforderungen der Bundesärztekammer und des Bundesgesundheitsamtes an Blutspender entsprechen (Hepatitis B, Lues, HIV) [58, $157,248,272,273]$. Inwieweit dies für Übertragungen von avitalen konservierten Geweben erforderlich ist, ist zur Zeit noch Gegenstand heftiger Diskussion. Bisher liegen keine Arbeiten vor, in denen über eine HIV-Übertragung durch konservierte avitale Gewebetransplantate berichtet wurde. Kürzlich wurden von der Deutschen Gesellschaft für Chirurgie „Richtlinien zum Führen einer Knochenbank“ herausgegeben, in denen diese Problematik berücksichtigt wird [139].

\subsubsection{Biologisches Schicksal von konservierten Stützgewebetransplantaten}

Nach Überwindung von kurzfristigen Unverträglichkeitsreaktionen ist die langfristige Haltbarkeit entscheidend, wobei langfristig hier mit 10 bis 20 Jahren gleichgesetzt werden muß.

Das biologische Ergebnis nach der Verpflanzung individualfremder Stützgewebe hängt von der Art, Ausdehnung, Stärke und Dauer entzündlicher Vorgänge ab. Dabei gewinnen die immunologischen (Antigenität) und mechanischen Faktoren besondere Bedeutung. Aus der Integration des Transplantats in den Empfängerorganismus können drei verschiedene Folgezustände resultieren:

1. Das Transplantat wird entweder durch das Eindringen neuer zellulärer Elemente derselben Art vom Empfänger umgebaut oder schrittweise resorbiert und durch Bindegewebe ersetzt.

2. Das transplantierte Gewebe wird als Fremdkörper abgekapselt.

3. Das Gewebe unterliegt einem kompletten Abbau und es entsteht ein neuer Defekt.

Trotz der zahlreichen tierexperimentellen Untersuchungen über das „in vivo“ Verhalten von konserviertem Bindegewebe verbleiben noch viele offene Fragen. Ferner soll hervorgehoben werden, daß für den Erfolg einer Transplantation der klinische Effekt und nicht die histologische Integrität entscheidend ist $[159,206]$.

\subsubsection{Natur der immunologischen Reaktionen}

Bei wenigen Fällen mit sowohl autologen als auch allogenen Geweben kann sich in den ersten zwei bis drei postoperativen Wochen eine Überwärmung im
Bereich des Transplantatlagers bemerkbar machen. Nach Behandlung mit Antibiotika und Corticosteroiden klingen diese als immunologische Abwehrreaktion zu deutenden Symptome meistens wieder ab. Es kann sich hierbei um allergische Spätreaktionen von Typ IV („excited-skin-syndrome“), die eine große Bedeutung für die postoperative Phase der Wundheilung und die Toleranz des Körpers gegenüber Transplantaten haben, handeln [66, 67, 68]. Die Differentialdiagnose zu einer Infektion ist aufgrund des klinischen Krankheitsbildes wohl nur ausnahmsweise möglich. Es wurde berichtet, daß durch die Beurteilung der T-Zell-Subpopulationen die Diagnose gesichert werden kann [68].

Eine besondere Problematik stellen die möglichen humoralen bzw. zellulären Immunreaktionen gegenüber zuvor vom Immunsystem ,sequestriertem" Knorpelgewebe dar. Solche Folgen können bei der Anwendung von autologem und allogenem Knorpelgewebe beobachtet werden. Hier muß man unterscheiden zwischen Immunreaktivitätszuständen, die als Folge einer Knorpeltransplantation entstehen sowie Situationen, bei denen die Immunreaktivität gegenüber Knorpelgewebe schon im Rahmen von Autoimmunerkrankungen mit Knorpelbefall (z.B. rheumatische Erkrankungen und rezidivierende Polychondritis) vorhanden waren. Details hierüber finden sich in Kapitel 3.1.4.

\section{Spezieller Teil}

\subsection{Knorpeltransplantation}

Es gibt kaum ein Thema in der rekonstruktiven Chirurgie im Kopf-Hals-Bereich, in dem klinisch und theoretisch so viele unterschiedliche Ergebnisse und Meinungen existieren, wie bei der Knorpeltransplantation $[114,125,114,138]$. Der Grund für diese divergierenden Beobachtungen ist, daß hier Transplantate unterschiedlicher Herkunft und Konservierungsart sowie verschiedener Transplantatlager verglichen wurden.

Autologer Rippenknorpel steht zwar in ausreichendem Maße zur Verfügung, jedoch ist die Entnahme mit einem weiteren operativen Eingriff verbunden, und das Problem einer ausreichenden biologischen Qualität ist aufgrund von Verkalkungsprozessen nicht zu unterschätzen. In der Regel bleibt autologer Knorpel vital und wird ohne Umbaumechanismen integriert [65]. Jedoch wird auch bei manchen autologen Knorpeltransplantationen eine Resorption beobachtet [114]. Letztere ist vor allem auf Ernährungsstörungen und Infektionen zurückzuführen. Hierbei ist von großer Bedeutung, in welchem 
Zustand sich das Operationsgebiet befindet. Neuerdings wird die Beteiligung von immunologischen Reaktionen, die im Rahmen von bereits vorliegenden Autoimmunerkrankungen entstanden sind, diskutiert [28].

Allogener Knorpel unterliegt wie jedes verpflanzte biologische Material einer mehr oder minder großen Teilresorption. Für die Resorption spielt die Oberfläche des Transplantates und das Volumen der Transplantatteile eine wesentliche Rolle. Zudem ist wichtig, in welches Lager das Transplantat implantiert wird und in welchem Zustand sich das Operationsgebiet befindet. Ein weiterer wichtiger Faktor für die Resorption ist die mechanische Beanspruchung dieser Transplantate durch Zug, Druck und Bewegung sowie die primäre Qualität des Knorpels, der bei älteren Spendern erhebliche Umbau- und Verkalkungszonen aufweisen kann [138].

Aus immunologischer Sicht ist es entscheidend wichtig, welche Art von Knorpelmaterial verwendet wird, ob es sich um autologes, allogenes oder xenogenes Gewebe handelt und auf welche Weise es aufbewahrt und konserviert wird.

\subsubsection{Konservierungsverfahren}

Über experimentelle Knorpeltransplantationen am Tier liegen zahlreiche Veröffentlichungen mit sehr widersprüchlichen Ergebnissen vor. Obwohl das in vivo Verhalten des Knorpeltransplantats in erheblichem Ausmaß von den Präparationsverfahren abhängig ist, kann man zusammenfassend zwei hauptsächliche Befundkonstellationen nach der Transplantation beobachten:

- Ausbildung eines konzentrischen Verkalkungsringes (teilweise Ossifizierung) [113, 148, 205, 206, 259, 262];

- Invasion von Bindegewebe und Gefäßen [112, 149, 162]. Die Einsprossung von Bindegewebe und Gefäßen bedeuten Resorption. Knorpel ist physiologischerweise avaskulär und resistent gegen das resorptive Eindringen neuer Gefäße. Dabei spielt ein sogenannter antiinvasiver, in der Matrix enthaltener Faktor, eine entscheidende Rolle [149]. Wird dieser Faktor durch Behandlung des Knorpels extrahiert, so ist die Resistenz gegen Gefäßeinsprossung vermindert oder aufgehoben.

Wesentlichen Einfluß auf resorptive Vorgänge von gelagertem Knorpel hat die Art der Konservierung, z.B. tritt nach Strahlensterilisation eine stärkere und schnellere Resorption auf als nach Gassterilisation [262]. Vergleichende Untersuchungen zeigen, daß vorheriges Kochen oder eine Vorbehandlung, z.B. mit Alkohol oder Formalin zu ungünstigen Resultaten führt [112]. Sailer [206] und von Freitag et al. [259] berichteten über positive Erfahrungen mit der Verwendung von lyophilisierten homologen Knorpeltransplantaten in der Mund-Kiefer-Gesichtschirurgie. Jedoch zeigen sie gewisse Zweifel bezüglich der langfristigen Haltbarkeit dieser Implantate. Die besten Ergebnisse im Kopf-Hals-Bereich weist mit Methiolat konservierter und sterilisierter Knorpel auf. Dieser Methode ist vor allen übrigen, im klinischen Bereich einfach anzuwendenden Verfahren, der Vorzug zu geben.

Obwohl nach unseren bisherigen Erfahrungen Chondrozyten als Einzelzellsuspensionen gut konservierbar sind [38], scheint die Kältekonservierung von Knorpelgewebe, sogar unter Anwendung von Gefrierschutz, immer eine irreversible Funktionsstörung der Chondrozyten zur Folge zu haben [248].

Die Anwendung von konservierten xenogenen Knorpeltransplantaten scheint auch möglich zu sein. Die Verwendung von konservierten Rinderknorpeltransplantaten wurde schon 1951 von Gillies und Kristensen beschrieben. Die Resultate waren aber wegen unvorhersehbarer Resorptionsvorgänge unbefriedigend [90, 93, 147]. Die Verwendung von Rinderknorpel wurde daher wieder verlassen bis Ersek et al. [69] über besseres Verhalten von Rinderknorpeltransplantaten nach einer kombinierten Behandlung mit Glutaraldehyd und Betabestrahlung berichteten. Die geringe Resorption wurde dem Umstand zugeschrieben, daß die Vorbehandlung eine Stabilisierung der Kollagenfasern zur Folge habe [70]. Dieses Verhalten wäre mit dem von allogenem Bankknorpel vergleichbar. Neue Berichte über klinische Erfahrungen bestätigen diese ersten Ergebnisse [140, 182].

\subsubsection{Antigenität von Knorpelgewebe}

Heyner [118] und Langer und Gross [155] berichteten anhand langfristiger histologischer Untersuchungen an allogenen Knorpeltransplantaten über das Vorhandensein von Lymphozyteninfiltraten. Anhand histologischer Schnitte beobachteten Westhues et al. [267] nach der Sensibilisierung eines Empfängertieres mit Hauttransplantaten desselben Spenders immunologisch kompetente Zellen gegen allogene Knorpeltransplantate. Bei einem umgekehrten Vorgang, d.h. nach einer Vorimmunisierung mit Knorpel, beschrieben diese Autoren auch eine beschleunigte Abstoßung von sekundären Hauttransplantaten. Einige Jahre davor beobachtete Craigmyle [49] eine beschleunigte Abstoßung von Hauttransplantaten nach Sensibilisierung von Kaninchen mit alloge- 
nem Knorpel. Diese Arbeiten bewiesen, daß nichtkonservierter allogener transplantierter Knorpel antigene Eigenschaften besitzt, die eine immunologische Abwehrreaktion des Empfängers auslösen, die wiederum zum Untergang des Transplantats führen kann.

Knorpel ist jedoch ein Gewebe mit einer besonderen immunologischen Kompetenz. Im Gegensatz $\mathrm{zu}$ anderen Geweben löst Knorpelgewebe nur geringe Abwehrreaktionen aus. Gibson $[89,91]$ sprach von einem „privilegierten“ Gewebe. Die „Einheilung“ des ,immunologisch privilegierten“ allogenen Knorpeltransplantats wird in der Literatur auf folgende zwei Eigenschaften zurückgeführt: die Gefäßlosigkeit und die Schutzfunktion der Knorpelmatrix. Diese letztere beruhe einerseits anscheinend auf der Verhinderung der Freisetzung antigenen Materials, was bewirkt, daß im Empfängerorganismus eine immunologische Abwehr mobilisiert werde. Auf der anderen Seite scheine die Matrix undurchlässig zu sein für Moleküle mit einem Molekulargewicht gröBer als 60000 Dalton, d.h. auch für Immunglobuline. Diese beiden Fakten werden dafür verantwortlich gemacht, daß die allogenen Antigene für den Empfänger wenig zugänglich sind.

Es liegt die Frage nahe, ob und welche Substanzen der Knorpelmatrix antigen sind. Einige Autoren haben untersucht, ob die Grundsubstanz über gewisse antigene Wirkungen verfügt [266, 268, 275]. Vor allem mit den Methoden der Hämagglutination, Hämagglutinations-Inhibition und Immundiffusion wurde die Grundsubstanz untersucht. Boake und Muir [24] wiesen am Kaninchen nach, daß Chondroitinsulfat nicht antigen wirkt. Sandson et al. [208] verpflanzten an Kaninchen Knorpel von Schweinen, Rindern und Menschen und fanden ähnliche Ergebnisse. Di Ferrante et al. [59] betrachteten die Proteoglykane als spezielspezifische Komponente der Grundsubstanz. Herman und Carpenter [116] zeigten durch ihre Studien mit Hilfe der Immundiffusion, daß die Glukosaminoglykane, nicht aber die Proteoglykane, antigen wirken. Kollagen halten unter anderen Steffen et al. [129] und Timpl [246] bei physiologischen Bedingungen nicht für antigen wirksam.

Mehrere Autoren [45, 118] untersuchten anhand von Tierexperimenten die immunologischen Reaktionen, die bei der Transplantation von isolierten allogenen Chondrozyten hervorgerufen werden. Unter anderem verglich Heyner [118] die Reaktion allogener Chondrozyten, die Ratten intralingual injiziert wurden, mit der Reaktion von intakten Knorpeltransplantaten in der Schenkelmuskulatur von den gleichen Ratten. Isolierte Chondrozyten, die vorsensibilisierten und nicht vorsensibilisierten Tieren injiziert wurden, verursachten immer immunologische

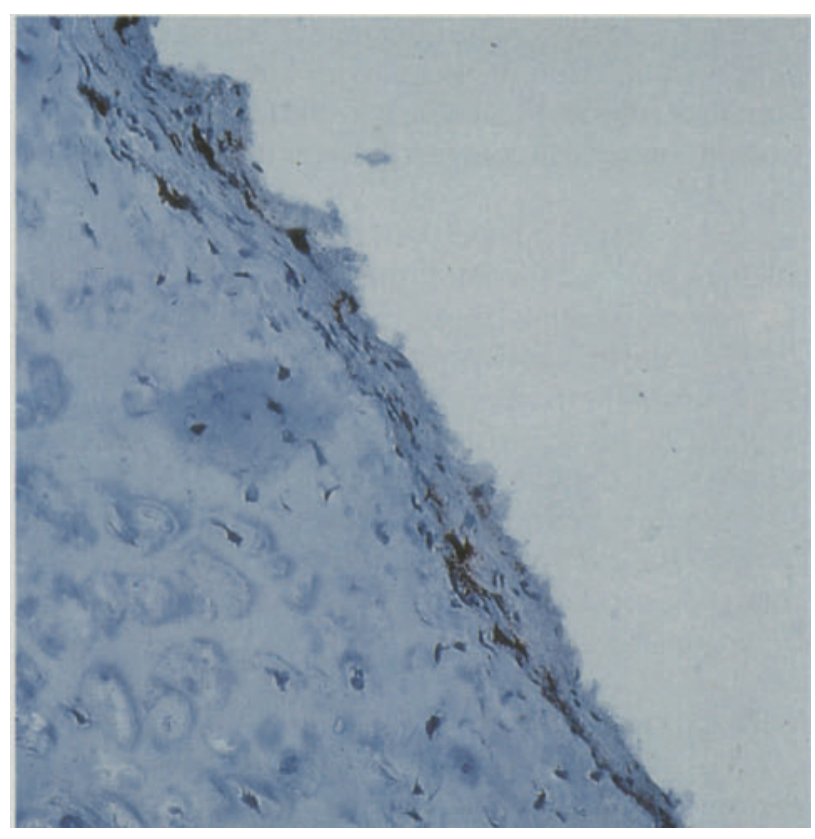

Abb. 6. Lichtmikroskopische Aufnahme eines NasenseptumSchnitts. Nur das Perichondrium weist HLA-Klasse-II-Antigene-tragende Zellen auf. Immunperioxidase-Methode. Vergrößerung $200 \mathrm{fach}$

Reaktionen, intakte Knorpeltransplantate dagegen nur, wenn der Empfänger vorsensibilisiert war. Man nahm daher an, daß die Chondrozyten stark antigen wirksam und durch die Knorpelmatrix für den Empfänger wenig zugänglich sind [64].

\subsubsection{Rolle der HLA-Klasse-II-Antigene im immunologischen Verhalten allogener Knorpeltransplantate}

Mehrere in vitro und in vivo Untersuchungen an Tieren und Menschen haben sich mit dem Nachweis von Transplantationsantigenen im Knorpel beschäftigt. 1965 konnte Stjernsward [232] zeigen, daß der Gelenkknorpel der Maus Transplantationsantigene besitzt, welche nach zusätzlicher Hauttransplantation die Entwicklung hämagglutinierender Antikörper induzieren können. Elves [63] demonstrierte, daß Gelenk-Chondrozyten vom Schaf im Vergleich zu Lymphozyten MHC-Antigene besitzen, diese aber erst vollständig exprimieren, wenn die sie umgebende Matrix entfernt wurde und sie länger mit Antikörpern inkubiert wurden. Gertzbein und Lance [86] und Malsed und Heyner [62] beschrieben aufgrund unterschiedlicher Methoden, daß isolierte GelenkChondrozyten von Ratten MHC-Antigene tragen. Tiku et al. [245] zeigten an Kaninchen, daß GelenkChondrozyten MHC-Klasse-II-Antigene aufweisen 
und daher als antigenpräsentierende Zellen funktionieren könnten. Alle bisher erwähnten Autoren beschäftigten sich mit hyalinem Knorpel. In Zusammenhang mit elastischem Knorpel konnte Jakse [128] mit Hilfe der qualitativen Immunofluoreszenz- und Immunperoxidase-Methode, Klasse-I- und KlasseII-Antigene an histologischen Schnitten von RattenOhrknorpel nachweisen. Diese früheren Untersuchungen bei Ratten und Kaninchen wiesen das Vorhandensein von Klasse-II-Antigenen im Knorpel nach. Eigene Untersuchungen haben gezeigt, daß menschliche Chondrozyten, in histologischen Schnitten und isoliert in Suspension, keine HLA-Klasse-IIAntigene aufweisen [32] (Abb. 6). Diese Ergebnisse legen nahe, daß menschliches Knorpelgewebe unter normalen Bedingungen im Gegensatz zu tierischem Knorpelgewebe keine Klasse-II-Antigene besitzt.

Unter bestimmten immunologischen Bedingungen, z.B. der „Graft-Versus-Host-Disease“ (GVHD) und lokalen Entzündungen kann die Expression von Klasse-II-Antigenen auf Zellen, auf denen normalerweise keine Klasse-II-Antigene nachweisbar sind, induziert werden $[5,10,52,76]$. Die Expression erfolgt unter Einfluß von Gamma-Interferon, das von stimulierten T-Lymphozyten freigesetzt wird [100]. Die Frage, ob eine Antigenmodulation an Knorpelzellen unter bestimmten immunologischen Situationen möglich ist, wurde mit Hilfe von monoklonalen Anti- körpern und rekombinantem Gamma-Interferon in einem in vitro Modell untersucht. Es konnte gezeigt werden, daß die drei HLA-Klasse-II-Antigene unter Zugabe von Gamma-Interferon auf Chondrozyten induziert werden (Abb. 7) [33] und daß die Klasse-IIAntigen-positiven Chondrozyten in der Lage sind, als antigenpräsentierende Zellen zu funktionieren [3]. Dies beweist, daß eine Induktion unter bestimmten immunologischen Bedingungen, z.B. nach der Transplantation durch Exposition im Empfänger, möglich ist. In einem Fall konnte eine in vivo Neuexpression von HLA-Klasse-II-Antigenen auf Chondrozyten eines abgestoßenen allogenen Knorpeltransplantats humaner Herkunft nachgewiesen werden. Ob eine ähnliche Induktion bei der Resorption von autologem Knorpel auftritt, ist bisher noch nicht untersucht worden.

Angeregt durch die Frage, ob eventuell das Perichondrium solche Antigene besitzt, wurde immunhistologisch untersucht, ob diese periphere Schicht von Knorpel Klasse-II-Antigene exprimiert. Hierbei konnte eine unterschiedliche Intensität der Anfärbung des jeweiligen Perichondriums von Ohr-, Nasenseptum- und Rippenknorpel sowie Trachea beobachtet werden [29, 37]. Dies beweist, daß die verschiedenen HLA-Klasse-II-Antigene in unterschiedlichem Ausmaß im Perichondrium jeder Knorpelart vorhanden sind. HLA-DR-Antigene waren am häu-

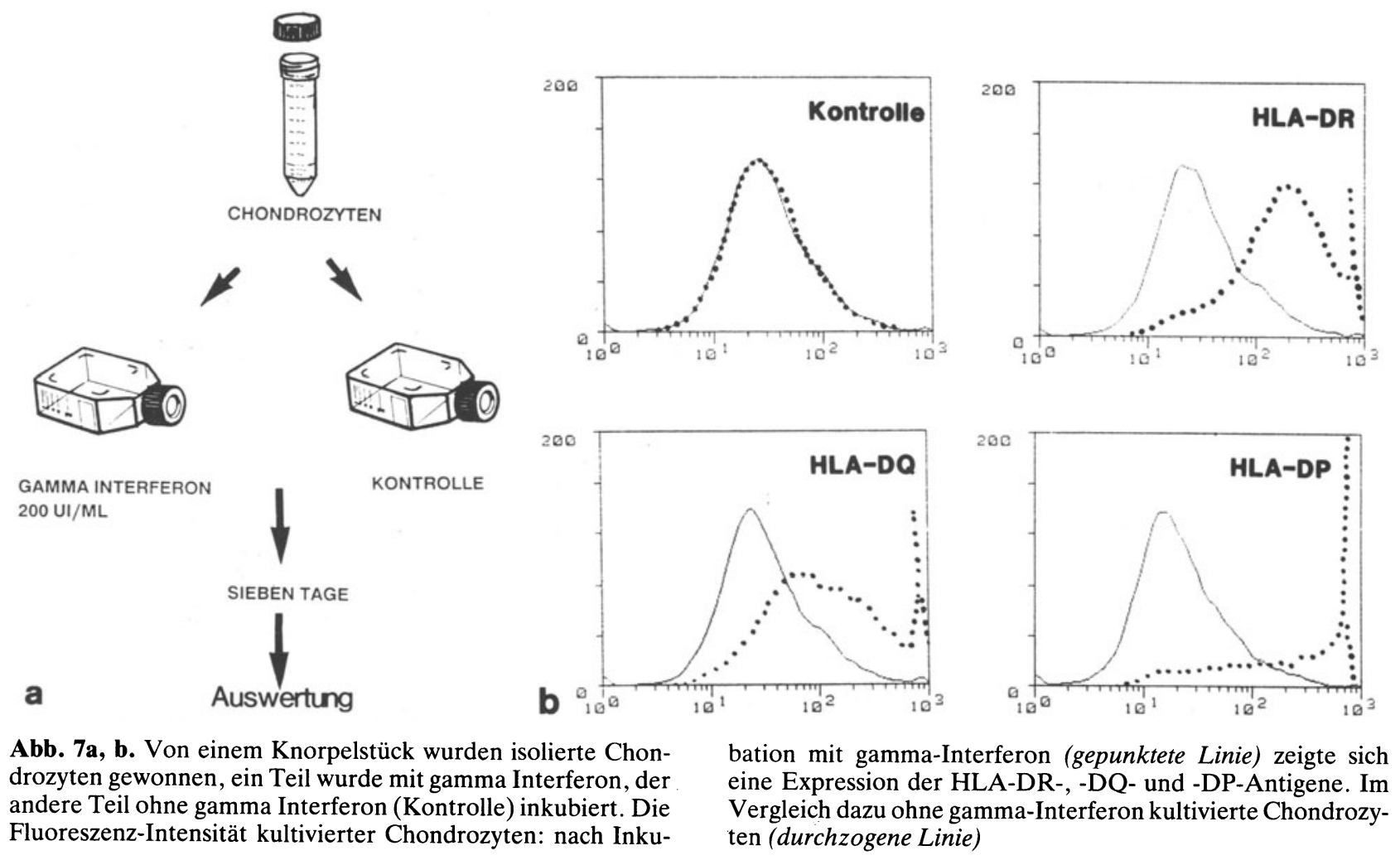


figsten vorhanden (Abb. 6). Die Bedeutung dieser Unterschiede bleibt nach wie vor unbekannt $[55,177$, 187]. Bekannt ist, daß die verschiedenen HLAKlasse-II-Antigene Unterschiede in der Fähigkeit zeigen, mit verschiedenen T-Lymphozyten zu interagieren [97]. An der Maus wurde festgestellt, daß die Aktivierung von Helfer- und Suppressor-T-Lymphozyten von zwei verschiedenen Klasse-II-Antigenen (I-A Antigene für die Helfer-T-Lymphozyten und I-E Antigene für die Suppressor-T-Lymphozyten) gesteuert wird [14, 183]. Die unterschiedliche Expression von HLA-DR-, HLA-DP- und HLA-DQAntigenen könnte die Antigenpräsentationskapazität der Zellen beeinflussen. Dadurch könnte die Immunantwort reguliert werden [129]. Nachdem im Perichondrium Klasse-II-Antigene beobachtet wurden, bestätigen diese Ergebnisse die klinischen Ansichten einiger Autoren, die die Anwendung allogener Knorpeltransplantate ohne Perichondrium befürworten $[114,138]$.

\subsubsection{Charakterisierung der immunologischen Reaktionen gegenüber Knorpeltransplantaten}

Die Unverträglichkeitsprobleme bei der Knorpeltransplantation (ohne vorherige Konservierung) zeigen sich in zwei verschiedenen Formen: als kurzfristige Abstoßungsreaktionen und als langfristige Teilresorptionen des verpflanzten Materials. Weiterhin zeigt der Klinikalltag Patienten, die im Rahmen von chirurgischen rekonstruktiven Eingriffen mehrfach Knorpeltransplantate erhielten, die jeweils abgestoBen bzw. resorbiert wurden.

Bei den langfristigen Resorptionen handelt es sich um Umbauvorgänge, die klinisch symptomlos verlaufen und die letztendlich eine Resorption des Materials bewirken. Histologisch befindet sich der transplantierte Knorpel in einer Umstrukturierung. Er weist in einzelnen Bezirken eine Demaskierung der Grundsubstanz sowie einen faser- und bindegewebigen Umbau auf. Um das Knorpelstück ist ein schmaler Saum mit Fibrohistiozyten geformt. Neutrophile Granulozyten, Lymphozyten oder Plasmazellen werden nicht beobachtet [259].

Bei der Gruppe mit den wiederholten Abstoßungen geben die klinischen Daten einen starken Hinweis dafür, daß sich bei diesen Patienten eine erworbene immunologische Reaktivität gegen zuvor vom Immunsystem sequestrierten Knorpelgewebe entwickelt hat. Genauso wie bei den destruktiven rheumatischen Gelenkerkrankungen erbrachte die Suche nach Hinweisen für die Beteiligung von Autoimmunmechanismen an diesen Phänomenen, daß humorale Immunreaktionen im Sinne einer Autoantikörperbil- dung gegen antigene Strukturen des Knorpels wie Kollagene und Chondrozytenproteine eine Rolle spielen. Im Serum dieser Patienten konnten mittels ELISA hohe Titer von Autoantikörpern gegen Chondrozyten und gegen sowohl denaturiertes als auch nicht denaturiertes Kollagen Typ IX und XI nachgewiesen werden. Inwieweit eine zelluläre Immunantwort bei diesen Umbauvorgängen eine Rolle spielt, wird zur Zeit untersucht [28].

\subsection{Knochentransplantation}

Ein Gebiet, auf dem sich der Einsatz kleiner allogener knöcherner konservierter Transplantate im Kopf-Hals-Bereich zweifelsohne bewährt hat, ist die Mittelohr-Chirurgie [66, 137, 191]. Dabei werden die allogenen Gehörknöchelchen mit Cialit vorbehandelt. Größere allogene Knochentransplantate stellen aufgrund ihrer mangelnden Integrationsfähigkeit und ihrer Antigenität und der damit zum Teil größeren Infektionsanfälligkeit keine echte Alternative zum autologen Rippenknochentransplantat im KopfHals-Bereich dar.

Als entscheidende Parameter zur Beurteilung eines Knochentransplantates werden von Schweiberer et al. [216] die Transplantatstruktur, die Vitalität, die biomechanische Konstellation und die Kompatibilität angegeben. Mit anderen Worten scheinen folgende Eigenschaften den Wert eines Knochentransplantates auszumachen: Übertragung von kompatiblen, vitalen Zellen, Übertragung von osteoinduktiver Aktivität der Matrix und Übertragung einer Leitstruktur für einwachsende Gefäßstrukturen und neuzubildende Knochenlamellen.

\subsubsection{Antigenität von Knochengewebe}

Knochentransplantate werden durch körpereigenes Knochengewebe ersetzt. Weder das frische noch das konservierte Knochentransplantat bleibt nach der homologen Transplantation ganz oder $\mathrm{zu}$ wesentlichen Teilen im Empfängerorganismus [216].

Bei allogenen Knochentransplantaten kommt es nach einigen Tagen im Transplantatsgebiet zur Immunzellinfiltration, die zur Zerstörung des transplantierten Gewebes führt (Abb. 8).

Über die Bedeutung der verschiedenen Bausteine des Knochengewebes (Zellen, Matrix und Kollagen und Mineral) bei der Sensibilisierung und anschließenden Abwehrreaktion berichtet u.a. Friedlaender [80]. Daß es sich hierbei um ähnlich starke Abstoßungen handelt, wie sie bekanntermaBen bei Hauttransplantationen auftreten, zeigten 


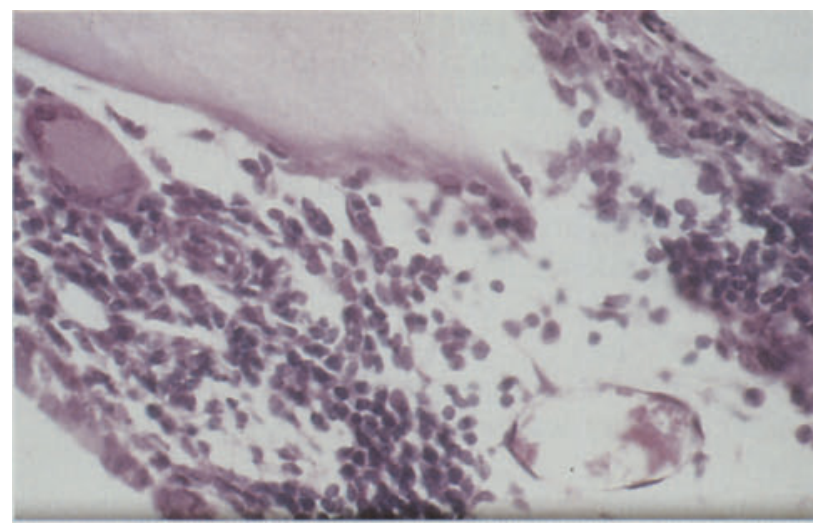

Abb. 8. Allogenes Knochentransplantat. Deutlich zu sehen ist die Präsenz eines ausgeprägten Immunzellinfiltrats. HE-Färbung. Vergrößerung 500fach. (Mit freundlicher Genehmigung von Prof. E. Kastenbauer, München)

Halloran et al. [103]. Heute wird im allgemeinen akzeptiert, daß bestimmte Knochenmarkszellen den am stärksten immunogenen Bestandteil von frischen allogenen Knochentransplantaten darstellen. Czitrom et al. [51] identifizierten Populationen von Granulozytenvorläuferzellen als potenteste Stimulatorzellen im Knochenmark. Diese Zellen tragen alle Charakteristika von dendritischen Zellen in peripheren lymphoiden Geweben und dürfen damit antigenpräsentierenden Zellen gleichgesetzt werden. $\mathrm{Ob}$ Osteoblasten, Osteozyten und Osteoklasten KlasseII-Antigene tragen und als antigenpräsentierende Zellen funktionieren, wird zur Zeit intensiv untersucht [221, 222].

\subsubsection{Osteoinduktion}

Die Ergebnisse der experimentellen und klinischen Untersuchungen der Knochentransplantation waren lange widersprüchlich, bis Axhausen [7] das zweiphasige Geschehen der Knochenneubildung beschrieb. Die erste und wichtigere Phase wird durch übertragene, lebende knochenbildende Zellen eingeleitet, die zweite durch Induktion unspezifischer Lagerzellen zu Osteoblasten.

Die Osteoinduktion stellt einen Mechanismus dar, bei dem es zu einem kaskadenartigen Ablauf biochemischer und zellulärer Reaktionen kommt [216]. Durch die Wirkung matrixeigener Makromoleküle erfolgt eine Differenzierung mesenchymaler Zellen zu Knorpel- und Knochengewebe. Neben den osteoinduktiven Matrixanteilen gibt es eine große Zahl anderer knochenspezifischer Stoffe, die das Knochenwachstum auf lokaler Ebene beeinflussen. In Wechselwirkung mit den calciumregulierenden Hormonen und anderen humoralen Wachstumsfak- toren haben sie nicht nur Einfluß auf die Knochenneubildung, sondern beteiligen sich auch an ständig ablaufenden Umbau- und Reparaturvorgängen. Folgende osteoinduktive Substanzen sind beschrieben worden: „bone morphogenetic protein“ [255], „extracellular matrix derived factor“ [199, 200], ,intramembranous osteogenetic factor“ [243] und „bone chemotactic factors" [175]. Neben diesen osteoinduktiven Substanzen, die aus demineralisierter Knochenmatrix isoliert werden können, produziert Knochen eine vermutlich große Zahl anderer Faktoren, die das Wachstum von Knochenzellen auf lokaler Ebene regulieren: „skeletal growth factor“ “ $[15,72$, $73,122,175]$, „bone derived growth factor“ " 44$]$ und „osteonectin“" $[239,240]$. Wie diese Stoffe in die regulatorischen Mechanismen der Zellen eingreifen ist Gegenstand intensiver Forschung [43, 111, 241, 254].

Im allgemeinen soll der verpflanzte Knochen aus eigener Kraft die Osteogenese in Gang setzen oder das Empfängerlager zur Osteogenese anregen. Die Überlegenheit autologer Transplantate beruht daher auf der Osteogenese durch beide Phasen, während bei der allogenen Transplantation nur die Induktion wirksam wird [132].

Erste Erfahrungen beim Einsatz von osteoinduktiven Substanzen wurden durch die klinische Verwendung von „Osteogenin-haltiger Gelatine“ [242, 244] und osteoinduktiver Implantate gewonnen [249]. Im Zeitalter der Gentechnik bietet es sich an, diese körpereigenen Eiweißmoleküle in genetisch veränderten Zellen in großer Menge herstellen zu lassen. Dies würde den Einsatz dieser osteoinduktiven Substanzen ermöglichen und damit eine $\mathrm{Be}$ schleunigung der Einheilung von Knochen bewirken.

\subsubsection{Konservierungsverfahren}

Bei der Konservierung von Knochengewebe bleiben die Grundsubstanz und damit die Interzellularsubstanz erhalten. Dadurch kann das allogene Transplantat nach Überwindung des Abstoßungsvorganges wieder induktiv spezifische Zellen der Knochenneubildung formen.

Es liegen zahlreiche klinische und experimentelle Untersuchungen zur Konservierung von Knochengewebe vor der Transplantation vor: Tiefgefrieren [95, 154, 172], Gefriertrocknen [252], Bestrahlung mit hochenergetischen Strahlen [185], Sterilisation, chemische Vorbehandlung (Formalin, Merthiolat, Cialit) [251], Entkalken und Enteiweißen [117, 176, 198]. Die erzielten Ergebnisse sind wegen unterschiedlicher und zum Teil recht grober Beurteilungskriterien, vor allem aber wegen noch allgemein unzureichender Kenntnis über immunologische Vorgänge 


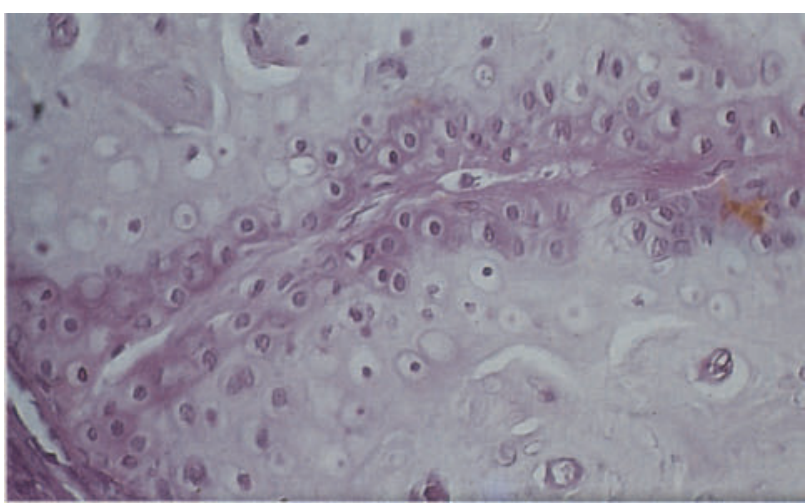

Abb. 9. Cialit-konserviertes allogenes Knochentransplantat. Deutlich zu sehen ist eine Knochenneubildung am Rand des Transplantats. HE-Färbung. Vergrößerung 500fach. (Mit freundlicher Genehmigung von Prof. E. Kastenbauer, München)

bei der Knochentransplantation, nicht miteinander vergleichbar. Trotzdem liegen sorgfältige klinische Untersuchungen vor, wie die von Weaver [263] oder Jonck [130], die über gute Transplantationsergebnisse mit kältekonservierter homologer Spongiosa berichten und eine osteoblastische Tätigkeit in $80 \%$ der Fälle nachweisen. Als Kriterium diente allerdings lediglich die Tatsache, daß - unabhängig von der Qualität - überhaupt Knochenbildung induziert wurde. Die Beschreibung negativer Ergebnisse, wie Stabler et al. [224] berichten, ist selten.

Cialit als Konservierungsmittel für homologe Mittelohrgehörknöchelchen wurde 1966 von Marquet in die Ohrchirurgie eingeführt. Sein wesentlicher Vorzug im Gegensatz zu anderen, radikaleren Konservierungsverfahren ist die Erhaltung der biologischen Potenz; die Osteogenese zur Integration der transplantierten Ossikel in das Mittelohr wird nicht behindert [134, 135, 136] (Abb. 9). Verantwortlich hierfür ist die nur gering denaturierende Wirkung des Cialits, denn eine Osteogenese ist nur möglich, wie schon erwähnt wurde, wenn die ungeformten Interzellularsubstanzen erhalten bleiben. In der CialitKonservierung bleiben die mesenchymalen Strukturen erhalten.

All diese Verfahren beeinträchtigen aber sicher die Vitalität und zum Teil auch die mechanischen Eigenschaften des Knochens. Die Aktivierung der immunologischen Abwehr auf lösliche oder zellmembrangebundene antigene Stimuli erfolgt erst unter der Vermittlung von spezifischen Zellen, den sogenannten antigenpräsentierenden Zellen (siehe Punkt 3.1). Wendet man diese Aussage in der Knochentransplantation an, so bedeutet dies, daß durch Elimination dieser Zellen vor der Transplantation die Immunogenität eines Transplantates und damit auch die zu erwartende Immunantwort des Empfängers beträchtlich vermindert werden kann. Eine Methode, die zur selektiven Elimination der antigenpräsentierenden Zellen aus einem Organ führt, ist die in vitro Kultur [215]. Dabei sollen weder die Vitalität noch andere organspezifische Funktionen beeinträchtigt werden [250].

\subsubsection{Charakterisierung der immunologischen Reaktionen gegenüber Knochentransplantaten}

Beim Knochen wird der entscheidende Vorgang der Immunisierung zunächst durch oberflächlich liegende Transplantatzellen induziert. Nach 8 bis 30 Tagen kommt es im Transplantatgebiet zur Rundzellinfiltration, die zur Zerstörung der transplantierten Zellen (Abb. 8) und zum Abräumen des im Rahmen der 1. Phase der Osteogenese erzeugten Osteoids führt. Die bis dahin ins Transplantat eingesprossenen Gefäße gehen ebenfalls zugrunde. Erst nach dieser Phase beginnt die erneute Vaskularisierung des Transplantats und eine induzierte Osteogenese vom Lager her [132].

Die Notwendigkeit einer ABO- und HLA-Typisierung vor der Transplantation ist diskutiert worden und wird von Zentrum zu Zentrum verschieden gehandhabt. Während einige Zentren ABO- und sogar rhesuskompatibel transplantieren, nehmen andere Zentren darauf keine Rücksicht. Sensibilisierungen gegen Blutgruppenantigene sind möglich, haben aber keinen Einfluß auf den Erfolg der Transplantation. Bei späteren Transfusionen (oder Schwangerschaften) kann sich eine solche Immunisierung allerdings nachteilig auswirken. Friedlaender [80] fand bei 9 von 43 Patienten, die gefriergetrocknete Knochentransplantate erhalten hatten, HLA-Antikörper. Diese hatten jedoch keinen Einfluß auf das klinische Ergebnis der Transplantation. In den Untersuchungen von Mankin et al. [163] war bei $3 / 4$ der Patienten mit großen, gefrorenen allogenen Transplantaten ein gutes oder ausgezeichnetes funktionelles Ergebnis festzustellen. Antikörper gegen HLA-Antigene ließen sich allerdings bei fast allen, nämlich $94 \%$ dieser Patienten, feststellen. Die guten funktionellen Ergebnisse in diesen beiden Studien sprechen gegen eine klinische Relevanz dieser Immunisierung. Sie zeigen auch, daß die Behandlung des Transplantats, d.h. entweder Tieffrieren oder Gefriertrocknen, einen partiellen Einfluß auf die Immunogenität hat.

Die künftige Entwicklung homologer Knochentransplantationen läßt sich nur schwer beurteilen. Sichere Vorhersagen über den Erfolg oder die massive Abstoßung solcher Gewebeübertragungen sind bisher nicht möglich. Ungeklärt ist auch, ob die Berück- 


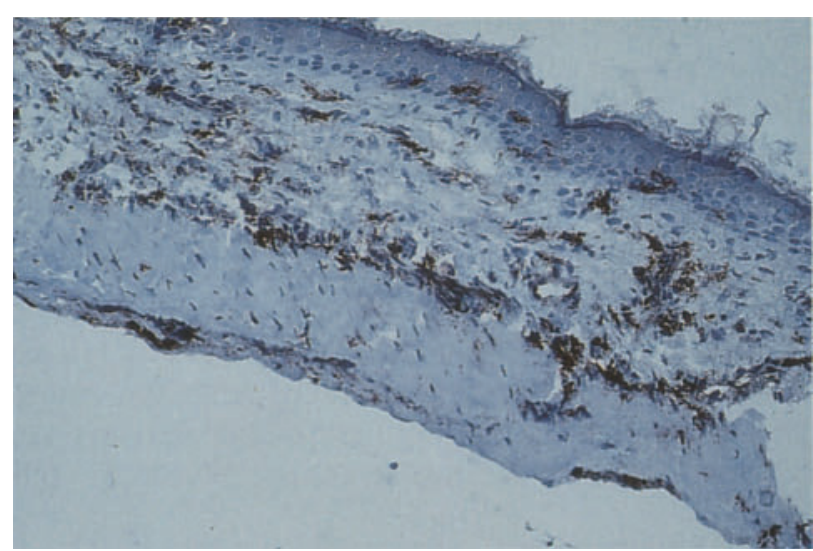

Abb. 10. Histologischer Schnitt durch ein menschliches Trommelfell. Deutlich positiv angefärbte HLA-DR-tragende Zellen. Immunperoxidase-Methode. Vergrößerung 200fach

sichtigung einer HLA-Typisierung hier bessere Ergebnisse [26, 178, 193] bringt oder vernachlässigt werden kann [25, 39, 56, 154]. Ungeachtet dessen wurden in jüngster Zeit durch Immunsuppression gute Ergebnisse bei der Transplantation massiver homologer Skelettanteile berichtet [1, 40, 95, 220].

\subsection{Bindegewebstransplantation}

$\mathrm{Zu}$ dieser Gruppe sind in erster Linie die chemisch konservierten allogenen Trommelfelltransplantate sowie die lyophilisierte und die mit organischen Lösungsmitteln behandelte Dura mater, Fascia lata und Fascia temporalis zu rechnen.

\subsubsection{Trommelfelltransplantate}

Seitdem Jean Marquet [165] die Anwendung von konservierten Trommelfelltransplantaten in der Ohrchirurgie beschrieb, findet dieses Verfahren verbreitet Anwendung in der rekonstruktiven Mittelohrchirurgie [166].

Die Transplantation von allogenen nicht konservierten Trommelfellen geht einher mit starken immunologisch bedingten Entzündungen und Reaktionen [150]. Der Grund hierfür liegt in einem hohen Gehalt an Klasse-II-Antigenen [34, 81]. Diese Antigene befinden sich vor allem in der äußeren Schicht (Abb. 10) und dies erklärt, warum diese Schicht nach der Transplantation verloren geht $[83,161]$.

Durch die Konservierung der Transplantate in Cialit-Lösung wird die Löslichkeit der Proteine erniedrigt und die Freisetzung der Antigene verzögert, so daß diese Transplantate mit einem besseren Resultat einheilen [136]. Durch die Konservierungsver- fahren Alkohol, Formaldehyd und Cialit werden diese Antigene zerstört [30, 81]. Die konservierten Transplantate haben damit zwar eine verminderte aber noch vorhandene Antigenität [81, 151, 184, 256, 257]. Bei diesen Transplantaten kann man immunhistologisch das Vorhandensein eines mononukleären Infiltrats feststellen.

Das Mittelohr wurde zunächst in der Literatur als ein privilegierter Ort zur Gewebetransplantation bezeichnet. Jedoch haben jüngere Untersuchungen gezeigt, daß sowohl der afferente als auch der efferente Arm der Immunantwort im Mittelohr intakt sind [83, $256,258]$.

\subsubsection{Bindegewebstransplantate}

Hierbei sollen als Hauptrepräsentanten allogene Dura mater, Fascia lata und Fascia temporalis vorgestellt werden.

Die Anwendung lypophilisierter Dura Mater als Gewebeersatz wurde in Tierversuchen erprobt [188, 246] und hat sich rasch in der Wiederherstellungschirurgie als ein unersetzliches Mittel zur Deckung von Gewebsdefekten herausgestellt. Die Gefriertrocknung ist jedoch ein relativ aufwendiges Verfahren und führt außerdem zu einer Hohlraumbildung innerhalb der kollagenen Faserstruktur, da es durch die Ausbildung von Eiskristallen zu einer Sprengung der Kollagenfibrillen kommt [189]. Eine Alternative stellt die Anwendung von lösungsmittelgetrocknetem Bindegewebe dar. Dabei erfolgt der Wasserentzug nicht durch Lypophilisation, sondern durch organische Lösungsmittel. Mehrere Arbeiten über die gute Gewebeverträglichkeit dieser lösungsmittelgetrockneten Dura mater im Tierexperiment liegen vor [233, 234, 235]. Ähnliche Erfahrungen zeigten sich bei der Anwendung lösungsmittelgetrockneter Fascia lata [16]. Diese Methode erzeugt Präparate, die frei von Antigenen, pyrogenen Stoffen und nicht kollagenem Eiweiß sind [269]. Durch experimentelle Untersuchungen wurde dafür der Nachweis erbracht, wobei es zu einem komplikationslosen Heilungsverlauf kommt. Dabei werden die Transplantate enzymatisch Schritt für Schritt abgebaut und das Transplantat dient als Schiene für den Ersatz durch vitales körpereigenes kollagenhaltiges Bindegewebe. Abstoßungsreaktionen fehlen, da Kollagen nur sehr schwach immunogen ist [246], zudem wird durch den Konservierungsprozeß auch diese Immunogenität weiter reduziert.

Bei Patienten mit Kollagenosen bzw. Autoimmunerkrankungen des Bindegewebes ist der Einsatz von Kollagenimplantaten allerdings nicht zu befürworten. Die bestehende Immunreaktivität gegen- 
über Kollagenmolekülen rufen stärkere Unverträglichkeitsreaktionen bei diesen Empfängern hervor [204].

\subsection{Tracheatransplantation}

Zur operativen Behandlung hochgradiger Stenosen des subglottischen Raumes und der Trachea stehen mehrere Verfahren zur Verfügung, wie die Querresektion der Trachea mit End-zu-Endanastomose, die Längsspaltung der Trachea und Tracheopexie sowie die Transplantation von äußerer autologer Haut bzw. Knorpel [123, 223, 264]. Da die autologen Transplantate in beschränktem Ausmaß zur Verfügung stehen, ist bei langen Defekten die Notwendigkeit eines Ersatzmaterials gegeben.

\subsubsection{Antigenität der Trachea}

Mehrere tierexperimentelle Untersuchungen wurden durchgeführt, um der Lösung des Problems eines Defektersatzes der Trachea mittels Transplantation näherzukommen. Erste Ergebnisse waren allerdings nicht sehr ermutigend. So berichteten Burket [41], Greenberg [99], Flemming und Hommerich [77], Tale und Maamies [236], Alonso et al. [2] und Farrington et al. [74] über die Abstoßung homotransplantierter Tracheateile an Hunden bzw. an Kaninchen.

Herberhold et al. [115] einerseits und von Ilberg et al. [127] andererseits berichteten 1977 erstmals über die erfolgreiche Einheilung von homotransplantierten chemisch konservierten Trachealsegmenten an Hunden bzw. Kaninchen. Die genannten Autoren konnten beobachten, daß die in die Trachea eingebrachten Transplantate an der luminalen Seite stets von einem normalen Flimmerepithel überwachsen wurden. Die Knorpelgrundsubstanz der Transplantate war in eine straffe Bindegewebsnarbe umgewandelt worden. Die entstandene Narbenplatte bildete zusammen mit dem neu überwachsenen Flimmerepithel der Tracheainnenseite ein in seiner Funktion vollkommenes Atemrohr. Staindl et al. und Lametschwandtner et al. [152, 225, 226] transplantierten erfolgreich Cialit-konservierte menschliche Tracheasegmente auf Hausschweine (Xenotransplantation) und beschreiben einen ähnlichen Verlauf wie bei der allogenen Transplantation.

Bei tierexperimentellen Untersuchungen mit nicht-konserviertem Tracheamaterial konnte gezeigt werden, daß die verpflanzten Tracheaanteile starke immunologische Reaktionen im Empfängerorganismus auslösten. Die Heftigkeit der immunologischen
Abwehrreaktionen wird von der Länge des Tracheatransplantates beeinflußt [17].

Bei Abstoßungsreaktionen nach Tracheatransplantation wird zuerst die Schleimhaut der Transplantate zerstört und langfristig durch eine vom Empfänger stammende Schleimhaut ersetzt [18, 19, 20, 152, 211, 225, 226, 219]. Jedoch ist die Möglichkeit des Ersatzes der abgestoßenen Schleimhaut von der Größe des Transplantates abhängig. Auf langen transplantierten Tracheastrecken fehlt das funktionstüchtige Flimmerepithel endgültig und es kommt zu einem Verlust der mucociliaren Sekretclearance.

In Hinblick auf eine später eventuell in der Klinik durchzuführende Tracheatransplantation müssen beide Mechanismen beherrscht werden: Die Antigenität und der Schleimtransport.

In Anlehnung an die bewährte Immunsuppressiva-Behandlung zur Unterdrückung der AbstoBungsreaktion gegen vitale Transplantate, wurden von Schmidt et al. [212] die Möglichkeit der Transplantation von allogenen vitalen Tracheatransplantaten an Inzuchtsstämmen von Ratten untersucht. Die Ergebnisse zeigten, daß ohne Immunsuppression kein Tier 30 Tage überlebte. Wurde jedoch immunsuppressiv behandelt, so konnten durch Gabe von Cyclosporin signifikant verlängerte Überlebenszeiten erzielt werden. Diese Ergebnisse deuten darauf hin, daß bei großen Tracheasegmenten eine allogene vitale Transplantation klinisch möglich sein könnte.

In Hinblick auf den Schleimtransport bei langen transplantierten Tracheastrecken wird heutzutage die Implantation von in vitro gezüchtetem Flimmerepithel diskutiert [71, 119, 133, 243].

Frühere Untersuchungen an tierexperimentellen Modellen, vor allem Rattenmodellen, zeigten, daß die Trachea Träger von Transplantationsantigenen ist [20]. Untersuchungen an Menschen konnten Klasse-II-Antigene-tragende Zellen in der Schleimhaut und in den Trachealdrüsen, nicht jedoch im Knorpelgewebe (Abb. 11) nachweisen. Diese Befunde zeigen, daß die Trachealschleimhaut in erheblichem Ausmaß Träger von Transplantationsantigenen ist, und erklärt, warum das menschliche Tracheatransplantat eine starke immunogene Wirkung auf den Empfängerorganismus ausübt [31].

\subsubsection{Einfluß unterschiedlicher Konservierungs- verfahren auf die Antigenität der Trachea}

Die Implantation konservierter, avitaler Tracheasegmente erscheint als eine Möglichkeit, immunologische Abwehrreaktionen zu verhindern. Bei der Kon- 


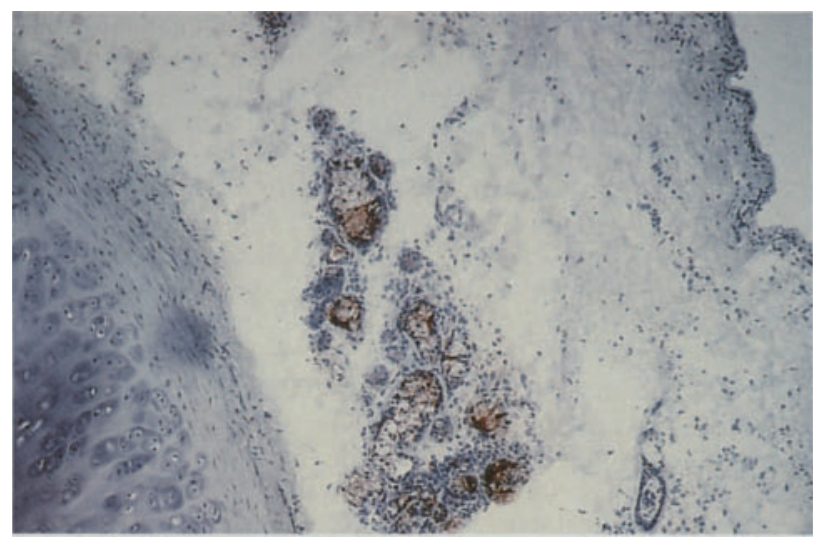

Abb. 11. Querschnitt durch eine menschliche Trachea. Schleimhaut und die Trachealdrüsen zeigen HLA-DR-Antigene. Immunperoxidase-Methode. Vergrößerung 100fach servierung sollen die biomechanischen Eigenschaften der Trachea wenn möglich nicht betroffen werden [160].

Die Konservierung mit Merthiolat oder Cialit führt zu einer graduellen Auflösung der histologischen Strukturen und dadurch zu einem Verlust von Klasse-II-Antigen-tragenden Zellen. Die Konservierung mit Formaldehyd dagegen führt zu einer direkten Elimination der Klasse-II-Antigene unter Erhaltung der normalen histologischen Strukturen. Eine komplette Zerstörung von Klasse-II-Antigenen kann durch Konservierung mit Merthiolat oder Cialit erst nach 42 Tagen erreicht werden, unter der Konservierung mit Formaldehyd bereits nach sieben Tagen (Abb. 12). Eine Vorfixierung in Formaldehyd verbessert die Strukturerhaltung [30].

In welchem Ausmaß diese chemisch konservierten humanen Tracheateile immunologische Reaktionen in einem menschlichen Empfänger auslösen, wurde kürzlich in vivo untersucht. Dabei wurde ein immunologisches Monitoring bei einem Patienten durchgeführt, der ein $8 \mathrm{~cm}$ langes Transplantat erhielt. Es wurden sowohl systemische als auch lokale immunologische Untersuchungen durchgeführt. Während des gesamten Beobachtungszeitraumes konnten keine Zeichen für eine Unverträglichkeitsbzw. Abstoßungsreaktion gefunden und damit die Hypothese unterstützt werden, daß chemisch konservierte Tracheatransplantate vom Empfänger nicht als fremd erkannt werden [36].

\section{Ausblick}

Für einen Teil der Gewebe oder Organe liegen exakte, allgemein anerkannte Empfehlungen zur Ge-

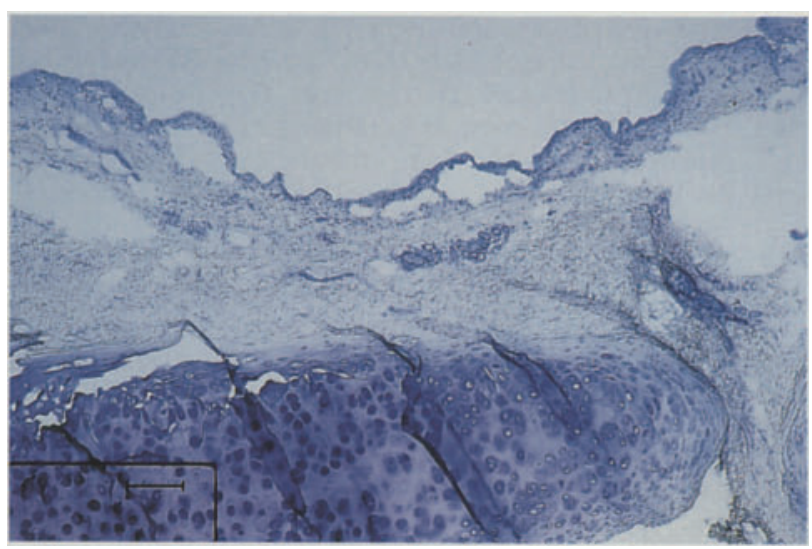

Abb. 12. Querschnitt durch eine Cialit-konservierte menschliche Trachea. Weder in der Schleimhaut noch in den Trachealdrüsen sind HLA-DR-Antigene nachweisbar. Immunperoxidase-Methode. Vergrößerung 100fach

winnung, Lagerung und Untersuchung des Transplantats vor. Auf dem Gebiet der Wiederherstellungschirurgie ist dies noch unzureichend übereinstimmend geregelt. Deshalb ist es wichtig, Bemühungen zu unternehmen, um in dieser Hinsicht allgemeine Richtlinien zu schaffen.

Die Verminderung der Immunogenität von Transplantaten ist das Ziel aller Konservierungsverfahren. Dabei sollte in Zukunft die Vitalität des Transplantates erhalten bleiben. Der aktuelle Stand der Wissenschaft und Technik erlaubt darüber hinaus die sterile Züchtung und Konservierung von vitalen Geweben. Hierbei ist es nötig, einerseits Differenzierungsprobleme von vitalen Geweben zu lösen und andererseits bessere Konservierungstechniken, die sowohl die Vitalität als auch die Qualität des Transplantats gewährleisten, zu entwickeln. Weiterhin können die wachsenden Kenntnisse über die Regulationsmechanismen des Regenerationsprozesses, sowie eine bessere Verfügbarkeit von Wachstumsfaktoren in Zukunft Möglichkeiten sowohl für die Beschleunigung der Einheilung von Transplantaten als auch für die Verfügbarkeit von in-vitro gezüchtetem autologem Gewebe eröffnen.

\section{Literatur}

1. Aebi M, Schwarzenbach O, Regazzoni P (1987) Experimentelle Knochenallotransplantate unter Immunsuppression mit mikrochirurgischer Revaskularisation. Hefte zur Unfallheilkunde 185:96-101

2. Alonso WA, Bridger OP, Bordley JE (1972) Tracheal transplantation in dogs. Laryngoscope 82:204-209

3. Alsalameh S, Jahn B, Krause A, Kalden JR, Burmester GR (1991) Antigenicity and accessory cell function of human articular chondrocytes. J Rheumatol 18:414-421 
4. Amos DB, Kotsyo DD (1980) HLA: A central immunological agency in man. Adv Hum Genet 10:137-142

5. Auböck J, Romani N, Grubauer G, Fritsch P (1986) HLA-DR expression on keratinocytes is a common feature of diseased skin. Br J Dermatol 114:465-472

6. Ax W (1988) Cytodiagnosis with monoclonal antibodies. Behring Inst Mitt 82:174-181

7. Axhausen W (1952) Die Knochenregeneration - ein zweiphasiges Geschehen. Zentralbl Chir 77:435-442

8. BAG (Bundesamt für Gesundheitswesen Schweiz) (1986) Desinfektionsmittel beim Virus LAV/HTL V III. Bulletin des Bundesamtes für Gesundheitswesen. S 30-35

9. Ballieux RE (1987) Immune regulation in man. In: Veldman JE, Mc Cabe BF (Hrsg) Oto-Immunology. Kugler Publications Amsterdam Berkeley, S 9-14

10. Barclay AN, Mason DW (1982) Induction of Ia antigen in rat epidermal cells and gut epithelium by immunological stimuli. J Exp Med 156:1665-1680

11. Barland P, Rosamond J, Sandson J (1966) Immunofluorescent studies of human articular cartilage. Ann Rheum Dis 25:156-164

12. Barre-Sinoussi F, Nugeyre MT, Chermann JC (1985) Resistance of AIDS virus at room temperature. Lancet II: $721-722$

13. Batchelor JR, Welsh KI, Maynard A, Burgos H (1979) Failure of long surviving, passively enhanced kidney allografts to provoke T-dependent alloimmunity. J Exp Med 150:455-464

14. Baxevanis CN, Ishi N, Nagy ZA, Klein J (1982) Role of the E-k molecule in the generation of suppressor T cells in response to LDH-B. Scand J Immunol 16:25-31

15. Baylink DJ, Farlay J, Howard G, Drivdahl R, Puzas E, Masuda T, Ivey J, Gruber H (1982) Coupling factor. In: Massry SG, Letteri LM, Ritz E (Hrsg) Regulation of phosphate and mineral metabolism. Plenum Press New York, S 409-420

16. Behbehani AA, Eichner E (1983) Erfahrungen mit lösungsmittelgetrockneter Fascia lata bei operativen Eingriffen im Hals-Nasen-Ohrenbereich. Laryng Rhinol Otol 62:548-551

17. Beigel A (1986) Immunologische Gesichtspunkte bei der Verpflanzung von allogenen (homologen) Trachealanteilen. In: Kastenbauer E, Wilmes E, Mees K (Hrsg) Das Transplantat in der plastischen Chirurgie. Carl Sasse Rothenburg, S 344-346

18. Beigel A, Müller-Ruchholtz W (1984) Tracheal transplantation. I. The immunogenic effect of rat tracheal transplants. Arch Otorhinolaryngol 240:185-192

19. Beigel A, Müller-Ruchholtz W (1984) Tracheal transplantation. II. Influence of genetic difference and degree of sensitization on reactions to the tracheal transplant. Arch Otorhinolaryngol 240:217-225

20. Beigel A, Steffens-Knutzen R, Müller B, Schumacher U, Stein H (1984) Tracheal transplantation. III. Demonstration of transplantation antigens on the tracheal mucosa of inbred rat strains. Arch Otorhinolaryngol 241:1-8

21. Berah M, Hors J, Dausset J (1970) A study of HLA-A antigens in human organs. Transplantation 9:185-192

22. Bernoulli C, Siegried J, Baumgartner G, Regli F, Rabinowicz T, Gajdusek DC, Gibbs CF (1977) Danger of accidental person-to-person transmission of CreutzfeldtJakob disease by surgery. Lancet I:478-479

23. Bezwoda WR, Dansy R (1989) Monocyte function after bone marrow transplantation: role of Ia+ monocytes in graft-versus-host disease. Clin Transplantation $3: 264-268$

24. Boake WC, Muir H (1955) The non-antigenicity of chondroitin sulphate. Lancet II:1222-1223
25. Boerner M (1985) Experimentelle Grundlagen und klinische Erfahrungen bei der Anwendung allogener Spongiosa. Aktuell Traumatol 15:210-218

26. Bos GD, Goldberg UM, Zika JM, Heiple KG, Powell AE (1983) Immune responses of rats to frozen bone allografts. J Bone Joint Surg (Am) 65:239-240

27. Brown P, Gibbs JC, Gajdusek DC, Cathala F, La Bauge R (1986) Transmission of Creutzfeldt-Jakob disease from formalin paraffin-embedded human brain tissue. $\mathrm{N}$ Engl $\mathrm{J}$ Med 315:1614-1615

28. Bujía J, Pitzke P, Wilmes E, Hammer C, Reiman V, Kastenbauer E (1990) Immunological response towards cartilage cells in man: Relevance to cartilage grafting in otolaryngology. Proceedings of the Third International Academic Conference in Immunobiology in Otolaryngology. Kugler Publications Amsterdam Berkeley

29. Bujía J, Wilmes E, Hammer C (1990) Allogene Knorpeltransplantation: Immunhistochemische Untersuchungen zur Antigenität des Perichondriums. Z Exp Chirurg Transplant Künst Org 23:202-204

30. Bujía J, Wilmes E, Hammer C, Kastenbauer E (1990) A comparison of class II antigenicity of human tracheal allografts stored in Cialit and in Merthiolate. Laryngoscope 100:1337-1340

31. Bujía J, Wilmes E, Hammer C, Kastenbauer E (1990) Tracheal Transplantation: Demonstration of HLA Class II Subregion Gene Products of Human Trachea. Acta Otolaryngol (Stockh). 110:149-154

32. Bujía J, Wilmes E, Krombach F, Hammer C, Kastenbauer E (1990) Detection of class II antigens on human nasal cartilage. Am J Otolaryngol 11:339-344

33. Bujía J, Wilmes E, Krombach F, Hammer C, Kastenbauer E (1990) The effect of gamma-interferon on HLA class II antigen expression on isolated human nasal chondrocytes. Eur Arch Otorhinolaryngol 247:287-290

34. Bujía J, Wilmes E, Hammer C, Bartual J (1990) Presence and distribution of HLA-DR, HLA-DP and HLA-DQ antigens on human tympanic membrane. Acta Otolaryngol Esp 41:214-216

35. Bujía J, Reiman V, Pitzke P, Wilmes E, Holtmann S, Kastenbauer E (1990) In vitro Magnetresonanzspektroskopische Gütebestimmungen von Knorpeltransplantaten. Kongreßband der Jahrestagung der Deutschen Gesellschaft für Plastische- und Wiederherstellungschirurgie

36. Bujía J, Pitzke P, Krombach F, Hammer C, Wilmes E, Herberhold C, Kastenbauer E (1991) Immunological behaviour of preserved human tracheal allografts: Immunological monitoring of a human tracheal recipient. Clin Transplantation 5:376-380

37. Bujía J, Wilmes E, Hammer C, Kastenbauer E (1991) Class II Antigenicity of human cartilage: Relevance to the use of homologous grafts for reconstructive surgery. A Plast Surg 26:541-543

38. Bujía J, Pitzke P, Wilmes E, Hammer C (1991) Culture and cryopreservation of chondrocytes from human cartilage: Relevance for cartilage allograftig. ORL

39. Burchardt H (1983) The biology of bone graft repair. Clin Orthop 174:28-42

40. Burchardt H, Glowczewskie FP, Enneking WF (1981) Short term immunsuppression with fresh segmental fibular allografts in dogs. J Bone Joint Surg (Am) 63:411-445

41. Burket WC (1918) Transplantation of the trachea. Johns Hopk Hosp 29:35-40

42. Caca K, Schübel C, Krombach F, Kemkes BM, Hammer C (1989) DNA-Analysis of circulating blood mononuclear cells for diagnosis of rejection in heart transplant patients. Transplantation Proc 21:2523-2524 
43. Canalis E (1985) Effect of growth factors on bone cell replication and differentiation. Clin Orthop Relat Res 193:246-263

44. Canalis E, Peck W, Raisz LG (1980) Stimulation of DNA and collagen synthesis by autologous growth factor in cultured fetal rat calvaria. Science 210:1021-1023

45. Chesterman PJ, Smith AU (1968) Homotransplantation of articular cartilage and isolated chondrocytes. $J$ Bone Joint Surg 50B:184-197

46. Collins T, Korman AJ, Wake CT, Boss JM, Kappes DJ, Fiers W, Ault KA, Gimbrone MA, Strominger JL, Pober JS (1984) Immune interferon activates multiple class II major histocompatibility complex genes and the associated invariant chain gene in human endothelial cells and dermal fibroblasts. Proc Natl Acad Sci USA 81:4917-4921

47. Counce S, Smith P, Barth R, Snell GD (1956) Strong and weak histocompatibility gene differences in mice and their role in rejection of homografts of tumors and skin. Ann Surg 144:198-204

48. Cowdery JS, Tolaymat N, Weber SP (1991) The effect of partial in vivo depletion of CD4 $\mathrm{T}$ cells by monoclonal antibody. Transplantation 51:1072-1075

49. Craigmyle MBL (1958) An autoradiographic and histochemical study of long-term cartilage grafts in the rabbit. J Anat 92:467-472

50. Crumpton MJ, Snary D, Walsh FS, Barnstable CJ, Goodfellow PN, Jones EA, Boomer WF (1978) Molecular structure of the gene products of the human HLA system: isolation and characterization of HLA-A, -B, -C and Ia antigen. Proc R Soc Lond (Biol) 202:159-164

51. Czitrom AA, Axelrod T, Fernandez B (1985) Antigen presenting cells and bone transplantation. Clin Orthop 197:27-31

52. Daar AS, Fuggle SV, Fabre W, Ting A, Morris PJ (1984) The detailed distribution of MHC class II antigens in normal human organs. Transplantation 38:293-298

53. Dalgleish AG, Beverley PCL, Clapham PR, Crawford DH, Greaves MF, Weiss RA (1984) The CD (T4) antigen is an essential component of the receptor for the AIDS retrovirus. Nature 312:763-767

54. Dausset J (1958): Iso-leuco-anticorps. Acta Haematol 20:156-166

55. De Waal RMW, Bogman MJJ, Maas CN, Cornelissen LMH, Tax WJM, Koene RAP (1983) Variable expression of Ia antigens on the vascular endothelium of mouse skin allografts. Nature 303:426-429

56. Dederich R, Wolf L, Moeller F (1985) Homologe Knochentransplantation. Unfallchirurg 88:299-302

57. Deinhardt F, Koch M, Eggers HJ, Habermehl KO, Kurth R, Maass G (1986) Wie stabil sind LAV/HTLV-IIIViren? Dtsch Ärztebl 15:1045

58. DGHM (Deutsche Gesellschaft für Hygiene und Mikrobiologie) (1986) Merkblatt AIDS, Acquired Immune Deficiency Syndrome. Hyg Med 11:33-35

59. Di Ferrante N, Donnelly PV, Sajdera SW (1972) A segregated antigen in cartilage matrix. J Lab Clin Med 80:364-372

60. Dichtelmüller H, Stephan W, Prince AM, Gürtler L, Deinhardt F (1986) Inactivation of HTLV III/LAV by combined treatment with beta-propiolactone/UV irradiation. Int Soc Blood Transf Sydney 52:513-517

61. Dickson WA, Inglis TJJ (1988) Cialit preserved cartilage: failure to guarantee sterility. Br J Plast Surg 41:408-409

62. Duffy P, Wolf J, Collins G, De Voe AG, Streeten B, Cowen D (1974) Possible person-to-person transmission of Creutzfeldt-Jakob disease. N Engl J Med 290:692-693
63. Elves MW (1974) A study of the transplantation antigens on chondrocytes from articular cartilage. J Bone Joint Surg 56 B:178-185

64. Elves MW (1976) Newer knowledge of the immunology of bone and cartilage. Clin Orthop 120:232-259

65. Elwany S (1985) Histochemical study of cartilage autografts in tympanoplasty. J Laryngol Otol 99:637-642

66. Enzmann H (1982) Sensibilisierung bei der Verwendung von Fibrinkleber. Laryng Rhinol Otol 61:302-303

67. Enzmann H, Sheikh M (1983) „Angry Back“ - Ursache für Ertaubung nach Stapesplastik? Arch Klin Exp OhrenNasen-Kehlkopfheil (Suppl) II:349-353

68. Enzmann H, Daniel V (1991) Die Diagnose des „excitedskin-syndrome" aus dem Blut. Eine Hilfe für die plastische Chirurgie. Laryng Rhinol Otol 70:184-186

69. Ersek RA, Hart WG, Greer D, Beisang AA, Flynn PJ, Denton DR (1984) Processed bovine cartilage: an improved biosynthetic implant for contour defects. Ann Plast Surg 12:397-409

70. Ersek RA, Rothenburg PB, Denton DR (1984) Clinical use of an improved processed bovine cartilage for contour defects. Ann Plast Surg 13:44-50

71. Everitt JI, Hesterberg TW, Boreiko CJ (1990) The use of tracheal implants in toxicology and carcinogenesis research. Toxicol 60:27-40

72. Farley JR, Baylink DJ (1982) Purification of a skeletal growth factor from human bone. Biochem 21:3502-3507

73. Farley JR, Masuda T, Wergedal JE, Baylink DJ (1982) Human skeletal effect on bone cells in vitro. Biochem 21:3508-3513

74. Farrington WT, Hung WC, Binns PM (1977) Experimental tracheal homografting. J Laryngol (Lond) 91:101-110

75. Faustman DL, Steinman RM, Gebel HM, Hauptfeld V, Davie JM, Lacy PE (1984) Prevention of rejection of murine islet allografts by pretreatment with anti-dendritic cell antibody. Proc Natl Acad Sci USA 81:3864-3868

76. Feldmann M (1987) Regulation of HLA class II expression and its role in autoimmune disease. In: Autoimmunity and autoimmune disease. Ciba Foundation, S $88-108$

77. Flemming J, Hommerich KW (1968) Homotransplantation der Trachea im Tierexperiment. Arch Otorhinolaryngol 191:724-727

78. Forsum U, Claesson K, Hjelm E, Karlsson-Parra A, Klareskog L, Scheynius A, Tjernlund U (1985) Class II transplantation antigens: Distribution in tissues and involvement in disease. Scand J Immunol 21:389-396

79. Forsum U, Klareskog L, Peterson PA (1979) Distribution of Ia-antigen-like molecules on non-lymphoid-tissues. Scand J Immunol 9:343-349

80. Friedlaender GE (1983) Bone and cartilage transplantation (editorial comment). Clin Orthop 174:1-4

81. Frootko NJ (1985) Immune responses in allograft tympanoplasty. In: Veldman JE, McCabe BF, Huizing EH, Mygind N (Hrsg) Immunobiology, Autoimmunity and Transplantation in Otorhinolaryngology. Kugler Publications, Amsterdam Berkeley, S 171-176

82. Fuggle SV, McWhinnie DL, Chapman JR, Taylor HM, Morris PJ (1986) Sequential analysis of HLA-class II antigen expression in human renal allografts. Induction of tubular class II antigens and correlation with clinical parameters. Transplantation 42:144-150

83. Gagnon NB, Piche J, Larochelle D, Williams ML (1979) Homografts of the middle ear: privileged tissue or privileged site. Arch Otolaryngol 105:35-38

84. Gartner S, Markovitz P, Markovitz DM, Betts RF, Popovic M (1986) Virus isolation from and identification of 
HTLV-III/LAV producing cells in brain tissue from an AIDS patient. JAMA 256:2365-2371

85. Gast GC, Veldman JE (1985) Human histocompatibility antigens and transplantation in otology. In: Veldman JE, McCabe BF, Huizing EH, Mygind N (Hrsg) Immunobiology, Autoimmunity and Transplantation in Otorhinolaryngology. Kugler Publications, Amsterdam Berkeley, S $161-163$

86. Gertzbein SD, Lance EM (1976) The stimulation of lymphocytes by chondrocytes in mixed cultures. Clin Exp Immunol 24:102-109

87. Gibbs CJ, Gajdusek CD, Latarjet R (1978) Unusual resistance to ionizing radiation of the viruses of kuru, Creutzfeldt-Jakob disease and scrapie. Proc Natl Acad Sci 75:6268-6270

88. Gibbs VC, Wood DM, Garovoy MR (1985) The response of cultured human kidney capillary endothelium to immunologic stimuli. Hum Immunol 14:259-269

89. Gibson T (1967) Cartilage grafts. In: Seifert KE, Geisendörfer R (Hrsg) Transplantation von Organen und Geweben. Thieme, Stuttgart, S 203-210

90. Gibson T, Davis WB (1953) The fate of preserved bovine cartilage implants in man. Brit J Plast Surg 6:4-25

91. Gibson T, Davis WB (1955) Some further observations on the use of preserved animal cartilage. Brit J Plast Surg $8: 85-92$

92. Gill RG (1990) Role of passenger leukocytes in islet allograft immunity. Clin Transplantation 4:176-180

93. Gillies H, Kristensen HK (1951) Ox cartilage in plastic surgery. Br J Plast Surg 4:63-73

94. Glasscock ME, Jackson CG, Knox GW (1988) Can acquired immunodeficiency syndrome and Creutzfeldt-Jakob disease be transmitted via otologic homografts? Arch Otolaryngol Head Neck Surg 114:1252-1255

95. Goldberg VM, Bos GD, Heiple KG, Zika JM, Powell AE (1984) Improved acceptance of frozen bone allografts in genetically mismatched dogs by immunosuppression. $\mathbf{J}$ Bone Joint Surg (Am) 66:937-950

96. Goldberg VM (1984) The immunology of articular cartilage. In: Moskowitz RW, Howell DS, Goldberg VM, Mankin HJ (Hrsg) Osteoarthritis, Diagnosis und Management. W. B. Saunders Company Philadelphia, pp 81-88

97. Gonwa TA, Picker LJ, Raff HV, Goyert SM, Silver J, Stobo JD (1983) Antigen-presenting capabilities of human monocytes correlates with their expression of HLA-DS, an Ia determinant distinct from HLA-DR. J Immunol 130:706-711

98. Gottesdiener KM (1989) Transplanted infections: donorto-host transmission with the allograft. Ann Intern Med 110:1001-1016

99. Greenberg SD (1958) Tracheal homografts in dogs. Arch Otorhinolaryngol 67:577-586

100. Gresser I (1984) The effect of interferon on the expression of surface antigens. In: Vilcek J, De Maeyer E (Hrsg) Interferons and the immune system. Elsevier Science, B.V. Amsterdam, S 113-121

101. Hagerty RF, Braid HL, Bonner WM, Hennigar GR, Lee WH (1967) Viable and nonviable human cartilage homografts. Surg Gynec Obstet 125:485-492

102. Hagerty RF, Calhoon TB, Lee WH, Cuttino JT (1960) Human cartilage grafts stored in merthiolate. Surg Gynec Obstet 110:229-233

103. Halloran PF, Lee E, Ziv I, Langer F (1979) Bone grafting in inbred mice: evidence for $\mathrm{H}-2 \mathrm{~K}, \mathrm{H}-20$, and non- $\mathrm{H}-2$ antigens in bone. Transplantation Proc 11:1507-1509

104. Hammer C, Land W, Stadler J, Koller C, Brendel W (1983) Lymphocyte subclasses in rejecting kidney grafts detected by monoclonal antibodies. Transplantation Proc 15:356-360

105. Hammer C, Land W, Koller C, Stadler J, Weber B, Welte M (1984) Analyse von Lymphozytensubpopulationen im zirkulierenden Blut und im Transplantat nach Nierentransplantation. In: Albert FW, Seybold-Epting W, Kreitter H (Hrsg) Praxis der Nierentransplantation (II). Schattauer, Stuttgart New York, S 295-304

106. Hammer C, Lersch C (1987) Hematological Cytology in organ transplantation. In: Baethmann A, Messmer K (Hrsg) Surgical Research: Recent Concepts and Results. Springer, Berlin Heidelberg, S 173-180

107. Hammer C, Klanke D, Lersch C, Dirschedl P, Kemkes BM, Gokel M, Reichenspurner H, Reichert B (1989) Cytoimmunologic monitoring (CIM) for differentiation between cardiac rejection and viral, bacterial, or fungal infection: Its specificity and sensitivity. Transplantation Proc 21:3631-3633

108. Hammer C (1989) Cytology in transplantation. Schulz RS, Percha am Starnbergersee

109. Hämmerling GJ (1976) Tissue distribution of Ia antigens and their expression on lymphocyte subpopulations. Transplantation Rev 30:64-69

110. Harding CV, Leyva-Cobian F, Unanue ER (1988) Mechanismus of antigen processing. Immunolog Rev 106:77-92

111. Hauschka PV, Mavrakos AE, Iafrati MD, Doleman SE, Klagsbrun M (1986) J Biol Chem 261:12665-12674

112. Held JA, Spirgi M, Zurbuchen P (1961) Die Homotransplantate mit lyophilisierten Knorpeln in der stomatologischen Chirurgie. Österr Z Stomat 58:58-60

113. Hellmich S (1974) Der Einfluß unterschiedlicher Konservierungsmethoden auf die biologische Qualität von Knorpelimplantaten. Laryng Rhinol 53:711-717

114. Hellmich S (1982) Fehler und Gefahren bei der freien Knorpeltransplantation im Gesichtsbereich. HNO 30:140-144

115. Herberhold C, Franz B, Breipohl W (1980) Chemischkonservierte menschliche Trachea als Prothesenmaterial zur Deckung trachealer Defekte. Laryng Rhinol 59:453-457

116. Herman JH, Carpenter BA (1975) Immunobiology of cartilage. Sem Arthr Rheum 5:1-40

117. Herndon $\mathrm{CH}$, Chase SW (1952) Experimental studies in the transplantation of whole joints. J Bone Joint Surg 34:564-578

118. Heyner S (1969) The significance of the intercellular matrix in the survival of cartilage allografts. Transplantation 8:666-677

119. Hicks WL, Ward R, Albino A, Wang R (1990) In vitro growth of respiratory epithelium. Otolaryngol Head Neck Surg 103:164

120. Hirschberg H, Braathen LR, Thorsby E (1982) Antigen presentation by vascular endothelial cells and epidermal Langerhans cells: The role of HLA-DR. Immunol Rev $66: 57-77$

121. Hirschberg H, Moen T, Thorsby E (1979) Specific destruction of human endothelial cell monolayers by antiDRw antisera. Transplantation 28:116-120

122. Howard GA, Bottermiller BL, Turner RT, Turner JI, Baylink DJ (1981) Parathyroid hormone stimulates bone formation: evidence for a coupling mechanism. Proc Natl Acad Sci USA 78:3204-3210

123. Hubbell RN, Zalzal G, Cotton RT, McAdams AJ (1988) Irradiated costal cartilage graft in experimental laryngotracheal reconstruction. Int $\mathbf{J}$ Ped Otorhinolaryngol $15: 67-72$ 
124. Huber C, Irschick E (1988) Cytokines in the regulation of allograft rejection. Bibl Cardiol 43:103-110

125. Huizing EH, Mackay IS, Petruson B, Rettinger G (1989) Reconstruction of the nasal septum and dorsum by cartilage transplants - autogenetic or allogeneic? Rhinol 27:5-10

126. Hüttenbrink KB, Weidenfeller P (1990) Sind Cialit-konservierte Ossikel als Mittelohrimplantate bakteriologisch noch vertretbar? Laryng Rhinol Otol 69:327-332

127. Ilberg Cv, Kitano S, Schmidt A (1977) Das Cialit-konservierte Trachealtransplantat. Laryng Rhinol 56:814-823

128. Jakse R (1987) Die Antigenität des Ohrknorpels und ihre Beeinflussung durch vitale Konservierung. Teil 2: Nachweis von Antigenen des Ohrknorpels: Tierexperimentelle Untersuchung an Ratten. Laryng Rhinol Otol $66: 362-365$

129. Janeway CA, Bottomly K, Babich J, Conrad P, Conzen S, Jones B, Kaye J, Katz M, Mcvay L, Murphy DB, Tite J (1984) Quantitative variation in Ia antigen expression plays a central role in immune regulation. Immunol Today 5:99-105

130. Jonck LM (1981) Allogenic bone transplantation, part 1. A review of the status of allogenic bone banks. S Afr Med J 60:428-430

131. Jongsma A, Someren H, Westerveld A, Hagemeijer A, Pearson P (1973) Localization of genes of human chromosomes by studies of human-Chinese hamster somatic cell hybrids. Hum Genet 20:195-202

132. Jungbluth KH, Meenen NM (1987) Besonderheiten der autologen und homologen Transplantation von Knochengewebe. Hefte zur Unfallheilkunde 185:73-76

133. Kaschke O, Gerhardt HJ, Böhm F, Wenzel M (1991) Treatment of tracheal atresia by implantation of autological respiratory cells. Abstractsbuch First International Laryngotracheal Reconstruction Symposium, Cleveland, S 566

134. Kastenbauer ER (1972) II. Die Umbauvorgänge in autogenen und allogenen Gehörknöchelchentransplantaten im Tierexperiment. Arch Klin Exp Ohren-Nasen-Kehlkopfheil 203:58-69

135. Kastenbauer ER (1972) Tierexperimentelle Untersuchungen über das immunologische Verhalten allogener Gehörknöchelchen-Transplantate. Arch Klin Exp Ohren-Nasen-Kehlkopfheil 201:332-350

136. Kastenbauer ER, Hochstraßer K (1973) Der Einfluß des Konservierungsmittels Cialit auf die Proteinlöslichkeit und die Antigenität von allogenen und xenogenen Gehörknöchelchen- und Trommelfelltransplantaten. Arch Otorhinolaryngol 203:225-231

137. Kastenbauer ER (1982) Fehler und Gefahren bei der Knochentransplantation. HNO 30:145-147

138. Kastenbauer ER (1983) Konservierung und Anwendungsmöglichkeiten allogener (homologer) Transplantate im Hals-Nasen-Ohrenbereich. HNO 31:371-380

139. Katthagen BD (1990) Richtlinien zum Führen einer Knochenbank. Deutsche Gesellschaft für Chirurgie - Mitteilungen. 1:29-31

140. Kau RJ, Morgenstern C (1986) Konservierter Rinderknorpel als Implantat zum Tracheaaufbau. In: Kastenbauer E, Wilmes E, Mees K (Hrsg) Das Transplantat in der plastischen Chirurgie. Karl Sasse, Rothenburg, S $341-343$

141. Kirkman RL, Shapiro ME, Carpenter CB, McKay DB, Milford EL, Ramos EL, Tilney NL, Waldmann TA, Zimmermann CE, Strom TB (1991) A randomized prospective trial of anti-TAC monoclonal antibody in human renal transplantation. Transplantation 51:107-113
142. Klareskog L, Forsum U (1986) Tissue distribution of class II transplantation antigens: presence on normal cells. In: Solheim BG, Moller E, Ferrone S (Hrsg) HLA class II antigens. Springer, Berlin, S 339-355

143. Klein-Szanto AJP, Terzaghi M, Mirkin LD, Martin D, Shiba M (1982) Propagation of normal human epithelial cell populations using an in vivo culture system. Am J Pathol 108:231-239

144. Köhler G, Milstein C (1975) Continuous cultures of fused cells secreting antibody of predefined specifity. Nature 256:495-497

145. Kootte AMM, Henny FC, Tanke HJ, Slats J, Van Es LA, Paul LC (1988) Enumeration of Leu2a +, Leu2a+-DR+, and Leu2a+-Leu15+ cells in peripheral blood of renal transplant patients. Transplantation 45:132-138

146. Kratzin H, Götz H, Thinnes FP, Kruse T, Barnikol HU, Wernet P, Hilschmann N (1986) Structure of Human Class II Antigens Expressed by a Homozygous Lymphoblastoid B Cell Line. In: Solheim BG, Moller E, Ferrone S (Hrsg), Springer-Verlag. S 49-70

147. Krüger E (1964) Absorption of human rib cartilage grafts transplanted to rabbits after preservation by different methods. Brit J Plast Surg 17:254-264

148. Krüger E (1964) Die Knorpeltransplantation. Experimentelle Grundlagen und klinische Anwendung in der Kiefer- und Gesichtschirurgie. C. Hanser, München

149. Kuettner KE, Pauli BU (1983) Vascularity of cartilage. In: Hall BK (Hrsg) Cartilage. Vol I. Academic Press New York, S 189-201

150. Kuijpers W, van den Broek P (1975) Biological considerations for the use of homograft tympanic membranes and ossicles. Acta Otolaryngol 80:283-293

151. Kuijpers W, Veldman JE, van den Broek P (1987) Immunobiology of allografts in the middle ear. In: Veldman JE, Mc Cabe BF (Hrsg) Oto-Immunology. Kugler Publications, Amsterdam Berkeley, S 107-117

152. Lametschwandtner A, Staindl O, Tholo S (1980) Ergebnisse heterologer Trachealtransplantationen im Tierexperiment. III: Licht-, raster- und transmissionselektronenmikroskopische Langzeitbefunde. HNO 28:37-42

153. Lamm LU, Friedrich.U, Petersen GB (1974) Assignment of the major histocompatibility complex to chromosome No. 6 in a family with a pericentric inversion. Hum Hered $24: 273-284$

154. Langer F, Czitrom A, Printzker KP, Gross AE (1975) The immunogenicity of allograft fresh and frozen allogenic bone. J Bone Joint Surg (Am) 57:216-220

155. Langer F, Gross AE (1974) Immunogenicity of allograft articular cartilage. J Bone Joint Surg (Am) 56:297-304

156. Laskin DM, Sarnat BG (1953) The metabolism of fresh, transplanted and preserved cartilage. Surg Gynecol Obstetr 96:493-499

157. Lean MC (1989) Technical manual for surgical bone banking. American Association of Tissue Banks, VA, USA

158. Lehmann M, Lersch C, Krombach F, Osterholzer G, Hammer C, Kemkes BM, Klanke D (1987) Cyto-Immunologisches Monitoring (ZIM) und Chemoluminescenz (CL) von Phagozyten des peripheren Blutes (PB) bei herztransplantierten Patienten. In: Peiper HJ (Hrsg) Chirurgisches Forum 87 für experimentelle und klinische Forschung. Springer, Berlin Heidelberg, S 211-215

159. Lexer E (1925) 20 Jahre Transplantationsforschung in der Chirurgie. Langenbecks Arch Klin Chir 138:251-302

160. Loennecken ICL, Brusis T, Fischer JH, Clahsen S (1988) Entwicklung eines kombinierten Verfahrens zur Konservierung allogener Trachealsegmente mittels Fixation und Bestrahlungsbehandlung. Eur Arch Otolaryngol Supp II: $289-290$ 
161. MacKinnon DM (1972) Homograft tympanic membrane in myringoplasty. Ann Otol Rhinol Laryngol 81:194-202

162. Malsed ZM, Heyner S (1976) Antigenic profile of the rat chondrocyte. Arthritis Rheum 19:223-231

163. Mankin HJ, Doppelt SH, Sullivan FR, Tomford WW (1982) Osteoarticular and intercalary allograft transplantation. Cancer 50:613-630

164. Marquardt P (1954) Arzneimittelforschung 8:481

165. Marquet J (1966) Reconstructive microsurgery of the eardrum by means of tympanic membrane homograft. Acta Otolaryngol (Stockholm) 62:459-467

166. Marquet J (1976) Ten years of experience in tympanoplasty using homologous implants. J Laryngol Otol 82:897-905

167. Marx RE, Carlson ER (1991) Creutzfeldt-Jakob disease from allogeneic dura: a review of risks and safety. J Oral Maxillofac Surg 49:272-274

168. Mason DW, Morris PJ (1986) Effector mechanismus in allograft rejection. Ann Rev Immunol 4:119-145

169. McDiarmid SV, Busuttil RW, Levy P, Millis MJ, Terasaki PI, Ament ME (1991) The long-term outcome of OKT3 compared with cyclosporine prophylaxis after liver transplantation. Transplantation 52:91-97

170. McKenna RM, Rush DN, Bakkestad-Legare P, Jeffery JR (1988) Interleukin-2, interferon and lymphotoxin in renal transplant recipients. Transplantation 45:76-81

171. Medawar PB (1963) Definition of the immunologically competent cell. In: Wolstenholme GEW, Knight J (Hrsg) The Immunologically Competent Cell: Its Nature and Origin. CIBA Foundation Study Group. S 58-70

172. Melves MW (1978) Cell mediated immunity to allografts of fresh and treated bone. Int Orthop 2:171-175

173. Mertens J, Ullmann U (1988) Clinical and bacteriological investigations of Cialit-preserved ossicles. Eur Arch Otorhinolaryngol 245:355

174. Miyashita K, Inuzuka T, Kondo H, Saito Y, Bujita N, Matsubara N, Tanaka R, Hinokuma K, Ikuta F, Miyatake T (1991) Creutzfeldt-Jakob disease in a patient with a cadaveric dural graft. Neurol 41:940-941

175. Mohan S, Linkhart T, Farley J, Baylink D (1984) Bone derived factors active on bone cells. Calcif Tissue Int 36:139-145

176. Mschvidobadse MV (1978) Allotransplantation sterilisierter Knochen und Halbgelenke bei Knochendefekten. Zentralbl Chir 103:1138-1148

177. Müller C, Ziegler A, Hadam M, Waller HD, Wernet P, Müller G (1985) Divergent Expression of HLA-DC/MB, $\mathrm{DR}$, and -SB region products on normal and pathological tissues as detected by monoclonal antibodies. Immunobiol 169:228-249

178. Muscolo DL, Kawai S, Ray RD (1976) Cellular and humoral immune response analysis of bone-allografted rats. J Bone Joint Surg (Am) 58:826-832

179. Naji A, Markmann JF, Barker CF (1987) Immunobiology of the allograft response. Diabetes Metab Rev 3:1037-1059

180. Naujoks J, Ohnsorge P, Hornung S (1978) Eine Gewebebank in der HNO-Praxis. HNO 26:325-329

181. Neumayer HH, Wagner K, Kresse S (1986) HTLV-IIIantibodies in patients with kidney transplants or on haemodialysis. Lancet I:497

182. Noverraz PMM, Rittersma J (1989) Erfahrungen mit Chondroplast in der ästhetischen Gesichtschirurgie. Fortschr Kiefer Gesichtschirurg 34:100-103

183. Oliveira DGB, Blackwell N, Virchis AE, Axelrod RA (1985) Thelper and T suppressor cells are restricted by the
$\mathrm{A}$ and $\mathrm{E}$ molecules, respectively in the $\mathrm{F}$ antigen system. Immunogen 22:169-175

184. Palva T, Taskinen E (1990) Inflammatory cells in chronic ear disease. Value of lymphocyte subset determination in ear surgery. Acta Otolaryngol (Stockh) 109:124-129

185. Pelker RR, Friedlaender GE, Markham TC (1983) Biomechanical properties of bone allografts. Clin Orthop 174:54-57

186. Perkins R (1970) Human homograft otologic tissue transplantation buffered formaldehyde preparations. Trans Am Acad Ophthalmol Otolaryngol 74:278-282

187. Pesando JM, Graf L (1986) Differential expression of HLA-DR, -DQ and -DP antigens on malignant B cells. J Immunol 136:4311-4318

188. Pesch HJ, Stöss H (1976) Dura-mater-Transplantate. Mechanische Eigenschaften und Gewebeverträglichkeit. Chirurg Aktuell 1:196-199

189. Pesch HJ, Stöss H (1977) Lösungsmittelgetrocknete Dura mater. Ein neues Dura-Transplantat im Tierversuch. Chirurg 48:732-736

190. Pichlmayer R, Lauchart W, Wonigeit K (1981) Allgemeines zur Physiologie und Pathophysiologie der Organtransplantation. In: Pichlmayr $\mathrm{R}$ (Hrsg) Transplantationschirurgie. Springer, Berlin, S 19-28

191. Plester D, Bootz F (1985) Transplantation von Gehörknöchelchen. In: Dietrich E (Hrsg) Organspende Organtransplantation. Indikationen, Techniken, Resultate. R. S. Schulz, Percha am Starnberger See, S 413-428

192. Pober JS, Gimbrone MA, Cortan RS, Reiss CS, Burakoff SJ, Fiers W, Ault KA (1983) Ia expression by vascular endothelium is inducible by activated $\mathrm{T}$ cells and by human gamma-interferon. J Exp Med 157:1339-1353

193. Popkirov S, Minev M (1976) Die klinische Bedeutung der immunoserologischen Befunde bei der Transplantation von Alloknochen. Arch Orthop Trauma Surg 85:289-298

194. Prichard J, Thadani V, Klab R, Manuelidis E, Hadler J (1987) Rapidly progressive dementia in a patient who received a cadaveric dura mater graft. JAMA 257:1036-1037

195. Prompt CA, Reis MM, Grillo FM, Kopstein J, Kraemer E, Manfro RC, Maia MH, Comiran JB (1985) Transmission of AIDS virus at renal transplantation. Lancet II:672

196. Qvigstad E, Bruserud O, Thorsby E (1986) The role of human class II molecules in activation of T4 Lymphocytes. In: Solheim BG, Moller E, Ferrone S (Hrsg) HLA class II antigens. Springer, Berlin, S 473-488

197. Ramos EL, Milford EL, Kirkman RL, Tilney NL, Strom TB, Shapiro ME, Waldmann TA, Wood IG, Rollins MR, Carpenter CB (1989) Differential IL-2 receptor expression in renal allograft recipients treated with an anti-IL-2receptor antibody. Transplantation 48:415-420

198. Ray RD (1972) Vascularisation of bone grafts and implants. Clin Orthop 87:43-48

199. Reddi AH (1983) Regulation of lacal differentiation of cartilage bone by extracellular matrix: a cascade type mechanism. In: Liss AR (Hrsg) Limb development and regeneration. Part B, S 261-268

200. Reddi AH, Anderson WA (1976) Collagenous bone matrix-induced endochondral ossification and hemopoiesis. J Cell Biol 69:557-572

201. Reiman V, Bujía J, Köck E, Holtmann S, Wilmes E, Kastenbauer E (1990) Bestimmung der Vitalitätsparameter von Knorpeltransplantaten mit Hilfe der Magnetresonanzspektroskopie. Biomed Technik 35:232-233

202. Reiman V, Bujía J, Pitzke P, Hochstrasser K, Kastenbauer E (1990) MR-Spektroskopische Prüfung der biolo- 
gischen Güte von Knorpeltransplantaten. Biomed Technik 35 (II):252-253

203. Reiman V, Bujía J, Pitzke P, Wilmes E, Hammer C (1991) Optimierung der Konservierung von Knorpeltransplantaten. Biomed Technik. 36:318-319

204. Remacle M, Chatelain B (1991) Immune response after collagen injection for laryngeal rehabilitation development of an enzyme-linked immunoabsorbent assay. Eur Arch Otorhinolaryngol 248:202-204

205. Sailer FH (1976) Experiences with the use of lyophilized bank cartilage for facial contour correction. J Maxillofac Surg 4:149-157

206. Sailer FH (1983) Transplantation of lyophilized cartilage in maxillo-facial surgery. Karger, Basel

207. Salahuddin SZ, Rose RM, Groopman JE, Markham PD, Gallo RC (1986) Human T-lymphotropic virus type III (HTLV-III) infection of human alveolar macrophages. Blood 68:281-284

208. Sandson J, Rosenberg L, White D (1966) The antigenic determinants of the proteinpolysaccharides of cartilage. $\mathrm{J}$ Exp Med 127:817-828

209. Schadel A, Löwer J, Seifert E (1991) Über die Problematik einer Knorpel-Knochenbank angesichts des HIVInfektionsrisikos. HNO 39:177-181

210. Schendel DJ, Johnson JP, Evans RL, Wank R (1984) Clonal expression of differentitation and Ia-like antigens on alloreactive human $\mathrm{T}$ lymphocytes. Eur J Immunol 14:363-368

211. Scherer MA, Ascherl R, Geissdörfer K, Mang W, Blümel G, Lichti H, Fraefel W (1986) Experimental bioprosthetic reconstruction of the trachea. Arch Otorhinolaryngol 243:215-223

212. Schmidt B, Beigel A, Wustrow J, Werner J (1989) Immunosuppression bei experimenteller Trachealtransplantation. Unterschiedliche Therapieschemata im Vergleich. Eur Arch Otolyrhinolaryngol (Suppl) II:300-301

213. Schroeder TJ, Weiss MA, Smith RD, Stephens GW, First MR (1991) The efficacy of OKT3 in vascular rejection. Transplantation 51:312-315

214. Schwarz A, Hoffmann F, Láge-Stehr J, Tegzess AM, Offerman G (1987) Human immunodeficiency virus transmission by organ donation. Outcome in cornea and kidney recipients. Transplantation 44:21-24

215. Schwarzenbach O, Aebi M, Czitrom AA (1988) Allogene Knochentransplantate nach in vivo Kultur. In: Hackenbroch MH, Reflor HJ, Wirth CJ (Hrsg) Knorpel-Knochen Transplantation. Thieme, Stuttgart New York, S $61-65$

216. Schweiberer L, Hallfeldt K, Mandelkow H (1986) Osteoinduktion. Orthop 15:3-9

217. Seiffert KE (1970) Biological aspects of collagenous homografts. Acta Oto-Rhino-Laryngol Belg 24:27-33

218. Seron D, Alexopoulos E, Raftery MJ, Hartley RB, Cameron JS (1989) Diagnosis of rejection in renal allograft biopsies using the presence of activated and proliferating cells. Transplantation 47:811-816

219. Sesterhenn K, Rose KG, Lennartz KJ (1979) Die Trachealtransplantation im Tierexperiment. Versuche an isohistogenen Rattenstämmen: IV. Histologische und historadiographische Befunde am Epithel. Laryng Rhinol 58:502-508

220. Siliski JM, Sompkin S, Green CJ (1984) Vascularized whole knee joint allografts in rabbits immunosuppressed with cyclosporin A. Arch Orthop Trauma Surg 103:26-35

221. Skjodt H, Hughes DE, Dobson PR, Russell RG (1990) Constitutive and inducible expression of HLA class II determinants by human osteoblast-like cells in vitro. $\mathrm{J}$ Clin Invest 85:1421-1426

222. Skjodt H, Moller T, Freiesleben SF (1989) Human osteoblast-like cells expression MHC class II determinants stimulate allogeneic and autologous peripheral blood mononuclear cells and function as antigen-presenting cells. Immunol 68:416-420

223. Spector JG, Anderson K (1986) Tracheostenosis. In: Cummings CW, Fredrickson JM, Harker LA, Krause CJ, Schuller DE (Hrsg) Otolaryngology-Head and Neck Surgery (III) CV Mosby Company, St. Louis Toronto, S 2433-2459

224. Stabler CL, Eismont FJ, Brown MD, Green BA, Malinin TI (1985) Failure of posterior cervical fusions using cadaveric bone graft in children. J Bone Joint Surg (Am) $67: 371-375$

225. Staindl O, Lametschwandtner A, Zimmermann G, Adam H (1979) Ergebnisse heterologer Trachealtransplantationen im Tierexperiment: I. Operationstechnik und erste licht- und rasterelektronenmikroskopische Befunde am Trachealepithel. HNO 27:7-13

226. Staindl O, Lametschwandtner A (1979) Die Ergebnisse heterologer Trachealtransplantationen im Tierexperiment: II. Licht-, raster- und transmissionselektronenmikroskopische Befunde am Trachealtransplantat. HNO 27:221-226

227. Starke G (1990) Possible virus contaminants in tissue banking. Beitr Orthop Traumatol 37:492-495

228. Steeg PS, Moore RN, Johnson HM, Oppenheim JJ (1982) Regulation of murine macrophage Ia antigen expression by a lymphokine with immune interferon activity. J Exp Med 156:1780-1783

229. Steffen C, Timpl R, Wolff J, Furthmayr H, Wick G (1967) Immunbiologie und Immunpathologie des Kollagens. Med Mitt 41:27-32

230. Steinman RM, Kaplan G, Winter MD, Cohn ZA (1979) Identification of a novel cell type in peripheral lymphoid organs of mice. V. Purification of spleen dendritic cells, new surface markers and maintenance in vitro. $J$ Exp Med 149:1-16

231. Steinmuller DR, Hayes JM, Novick AC, Streem SB, Hodge E, Slavis S, Martinez A, Graneto D, Pearce G (1991) Comparison of OKT3 with ALG for prophylaxis for patients with acute renal failure after cadaveric renal transplantation. Transplantation 52:67-71

232. Stjernsward J (1965) Studies in the transplantation of allogenic cartilage across known histocompatibility barriers. Bibl Haemat 23:197-204

233. Stöss H, Pesch HJ (1976) Zur Frage der Sensibilisierung nach mehrzeitigen Dura-mater-Transplantationen. Verh Dtsch Ges Path 60:330

234. Stöss H, Pesch HJ (1977) Mehrzeitige Transplantation von lösungsmittelgetrockneter Dura mater. Tierexperimentelle Untersuchungen zur Frage der Sensibilisierung. Fortschr Med 95:1018-1021

235. Stöss H, Pesch HJ, Wildenauer HD, Tulusan AA (1975) Licht- und elektronenmikroskopische Untersuchungen an Transplantaten mit Lösungsmitteln konservierter Dura mater im Tierversuch. Verh Dtsch Ges Path 59:569

236. Tale P, Maamies TJ (1968) Observation on tracheal reconstruction in experimental animals. Ann Chir Gynaec Fenn 57:495-502

237. Tange RA, Troost D, Limburg M (1990) Progressive fatal dementia (Creutzfeldt-Jakob disease) in a patient who received homograft for tympanic membrane closure. Eur Arch Otorhinolaryngol 247:199-201 
238. Tenner-Racz K, Racz P, Dietrich M, Kern P (1985) Altered folicular dendritic cells and virus-like particles in AIDS and AIDS-related lymphadenopathy. Lancet II: $105-106$

239. Termine JD, Kleinman HK, Whitson SW, Conn KM, McGarvey ML, Martin GR (1981) Osteonectin, a bonespecific protein linking mineral to collagen. Cell 26:99-105

240. Termine JP, Gehron RP, Fisher LW, Shimokawa H, Drum MA, Conn KM, Hawkins GH, Cruz JB, Thompson KG (1984) Osteonectin, bone proteoglycan, and phosphoryn defects in a form of bovine osteogenesis imperfecta. Proc Natl Acad Sci USA 81:2213-2217

241. Thielemann F, Holz U, Treuber U, Herr G (1987) Parakrine Regulationsmechanismen des Knochengewebes. Hefte zur Unfallheilkunde 185:35-42

242. Thielemann FW, Feller AM, Schmidt K (1984) Defektersatz mit „Osteogenin-haltiger Gelatine (OCG)“. Z Orthop 122:843-847

243. Thielemann FW, Schmidt K, Koslowski L (1982) Osteoinduction. Part II: Purification of the osteoinductive activities of bone matrix. Arch Orthop Trauma Surg 100:73-78

244. Thielemann FW, Schmidt K, Koslowski L (1983) Neue Aspekte in der Behandlung größerer Knochendefekte. Akt Traumatol 13:115-119

245. Tiku ML, Liu S, Weaver CW, Teodorescu M, Skosey JL (1985) Class II histocompatibility antigen-mediated immunologic function of normal articular chondrocytes. J Immunol 135:2923-2928

246. Timpl R (1969) Antigene Eigenschaften der Bindegewebsstrukturproteine. Mels Med Mitteilungen 43:29-38

247. Tomford WW (1983) Investigational approaches to articular cartilage preservation. Clin Orthop Rel Res 174:22-27

248. Tomford WW, Mankin HJ, Friedlaender GE, Doppelt SH, Gebhardt MC (1987) Methods of banking bone and cartilage for allograft transplantation. Orthop Clin North Am 18:241-247

249. Toriumi DM, East CA, Rosen DM, Chu G, Liu CC, Larrabee WF (1991) Bone-inducing implants in head and neck surgery: an experimental study. Laryngoscope 101:395-404

250. Träger J, Ascherl R, Blümel G, Hipp E (1988) Experimentelle Untersuchungen über Konservierungsmöglichkeiten von osteochondralem Gewebe. In: Hackenbroch MH, Reflor HJ, Wirth CJ (Hrsg) Knorpel-Knochen Transplantation. Thieme, Stuttgart New York, S 6-10

251. Tuli SM, Chaudhuri RH (1979) Effect of preimplantation treatment on the bone-forming potential of decalcified allogenic and homogeneic bone-matrix implants. Arch Orthop Trauma Surg 94:167-173

252. Turner DW, Melloning JT (1981) Antigenicity of freezedried bone allograft in peridontal osseous defects. J Peridont Res 16:89-99

253. Unanue ER (1984) Antigen-presenting function of the macrophage. Ann Rev Immunol 2:395-428

254. Urist MR, DeLange RJ, Finerman (1983) Bone cell differentiation and growth factors. Science 220:680-686

255. Urist MR, Sato K, Brownell AG, Malinin TI, Lietze A, Huo YK, Prolo DJ, Oklund S, Finerman GAM, DeLange RJ (1983) Human bone morphogenetic protein (hBMP) ${ }^{1}$ (41630). Proceedings of the society for experimental biology and medicine. 173:194-199

256. Veldman JE, Boezeman AJ, Overbosch HC, Sedee GA, Borst-Eilers E, Kuijpers W, van den Broek P, FeltkampVroom TM (1979) Middle ear transplantation: a new concept in clinical otology. In: Muller-Hermelink HK (Hrsg)
Advances in experimental medicine and biology, Vol 114, Function and structure of the immune system. Plenum Press New York, S 357-362

257. Veldman JE, Kuijpers W (1981) Antigenicity of tympanoossicular homografts of the middle ear: analyses of immune responses to viable and preserved grafts in animal models. Otolaryngol Head Neck Surg 89:142-152

258. Veldman JE, Kuijpers W, Overbosch HC (1978) Middle ear implantation ist place in the immunohistophysiology of lymphoid tissue. Clin Otolaryngol 3:93-102

259. von Freitag V, Handa Y, Beckers H, Rodemer H (1988) Histologische Befunde an lypophilisierten homologen Knorpeltransplantaten vom Menschen. Dtsch Z Mund Kiefer Gesichts Chir 12:397-403

260. Walsh LJ, Seymour GJ, Powell RN (1986) Modulation of class II (DR and DQ) antigen expression on gingival Langerhans cells in vitro by gamma interferon and prostaglandin E2. J Oral Pathol 15:347-351

261. Walsh LJ, Seymour GJ, Powell RN (1988) The regulation of Langerhans cell T6, DR and DQ antigen expression: an hypothesis. J Oral Pathol 17:43-46

262. Wangerin K, Evers R, Bumann A (1987) Verhalten unterschiedlich sterilisierter allogener Lyoknorpelimplantate im Tierexperiment. Dtsch $\mathrm{Z}$ Mund Kiefer Gesichts Chir 11:8-17

263. Weaver JB (1949) Experiences in the use of homogenous (bone bank) bone. J Bone Joint Surg (Am) 31:778-792

264. Weerda H (1985) Neue Gesichtspunkte in der konventionellen Trachealchirurgie. Arch Otorhinolaryngol (Suppl II):44-46

265. Welsh KI, Burgos H, Batchelor JR (1977) The immune response to allogeneic rat platelets; $\mathrm{Ag}-\mathrm{B}$ antigens in matrix form lacking Ia. Eur J Immunol 7:267-272

266. Westhues M (1971) Die antigene Wirkung des Knorpels. 5. Nachweis von Antikörpern gegen isologes Knorpelgewebe bei der Ratte. Laryng Rhinol 50:57-60

267. Westhues M, Brendel W, Land W (1970) Die antigene Wirkung des Knorpels. 2. Nachweis der antigenen Wirkung des transplantierten Knorpels durch die ,secondset-Reaktion“. Laryng Rhinol 49:808-815

268. Westhues M, Federspil P (1970) Die antigene Wirkung des Knorpels: 3. Knorpelzellen und Grundsubstanz und ihre antigene Wirkung. Laryng Rhinol 49:815-817

269. Willital GH (1976) Klinische Erfahrungen mit Duraimplantationen in der Neugeborenenchirurgie. Z Kinderchirurg 19:16-25

270. Wilmes E, Gürtler L, Wolf H (1987) Zur Übertragung von HIV Infektionen durch allogene Transplantate. Laryngol Rhinol Otol 66:332-334

271. Wiman K, Curman B, Forsum U, Klareskog L, Malmnästjernlund U, Rask L, Trägardh L, Peterson PA (1978) Occurence of Ia antigens on tissues of non-lymphoid origin. Nature 276:711-713

272. Wissenschaftlicher Beirat der Bundesärztekammer, Bundesgesundheitsamt (1988) Transfusion von Blut- und Blutbestandteilkonserven. In: Richtlinien zur Blutgruppenbestimmung und Bluttransfusion. Neufassung 1987, Deutscher Ärzteverlag, Köln

273. Wissenschaftlicher Beirat der Bundesärztekammer, Bundesgesundheitsamt (1990) Richtlinien zum Führen einer Knochenbank. Dtsch Ärztebl 87:41-44

274. Wustrow TPU, Kastenbauer E (1991) Wie ich es mache: Zur Nomenklatur der Transplantation in der Hals-NasenOhren-Heilkunde. Laryng Rhinol Otol 70:387-388

275. Yablon IG, Cooperband S, Covall D (1982) Matrix Antigens in Allografts. The Humoral Response. Clin Orthop 168:243-251 